\title{
PROSPECCIONES ARQUEOLÓGICAS Y GEOMAGNÉTICAS EN LOS CERROS DE LA CABEZA Y DEL MÁRMOL, SECTOR NORTE DEL POBLADO CALCOLÍTICO DE VALENCINA (SEVILLA). CAMPAÑA DE 2014
}

\author{
ARCHAEOLOGICAL AND GEOMAGNETIC SURVEYS IN CERRO DE LA CABEZA \\ AND CERRO DEL MÁRMOL, NORTHERN SECTOR OF THE COPPER AGE \\ SETTLEMENT OF VALENCINA (SEVILLE). CAMPAIGN IN 2014
}

\author{
ALFREDO MEDEROS* / JUAN MANUEL VARGAS** \\ THOMAS X. SCHUHMACHER $* * * /$ FRANK FALKENSTEIN****/THOMAS LINK****
}

\begin{abstract}
Resumen: En el presente artículo presentamos los resultados de una primera campaña de prospección en la supuesta área poblacional del yacimiento de Valencina de la Concepción, que se encuentra $6 \mathrm{~km}$ al oeste de la actual ciudad de Sevilla. En concreto efectuamos una prospección geo-magnética, una recogida de material en superficie y perforaciones manuales de las anomalías registradas en dos parcelas vecinas, situadas en la parte septentrional de Valencina. En resumen, en la campaña de prospección en la "Parcela Municipal del Cerro de la Cabeza" y la parte meridional de la parcela del "Cerro Mármol" se ha detectado una multitud de anomalías circulares y elipsoidales, que probablemente definen fosas, silos y "fondos de cabaña". Por otro lado se ha documentado una gran cantidad de anomalías lineales. Las perforaciones manuales realizadas nos permiten reconocer la mayoría de estas anomalías como fosos. De esta manera nos ha sido posible reconocer diversos fosos, quizás asociables a tres recintos, que han sido utilizados en distintos momentos y están situados en la parte septentrional de Valencina. La cerámica recogida durante la prospección de superficie nos permite datar la mayoría de los hechos documentados en el Calcolítico.
\end{abstract}

* Dpto. de Prehistoria y Arqueología, Universidad Autónoma de Madrid, Carretera de Colmenar Viejo, km 15, Cantoblanco, E-28049 Madrid, Email: alfredo.mederos@uam.es

** Museo de Valencina-Casa de Cultura, Plaza de España 9, E-41907 Valencina de la Concepción, Correo-e: jmvargas66@gmail.com.

*** Professur für Ur- und Frühgeschichtliche Archäologie, Institut für Archäologie, Denkmalkunde und Kunstgeschichte,

\begin{abstract}
The present article offers the results of a first survey campaign in the supposed settlement area of the site of Valencina de la Concepción, which is situated $6 \mathrm{~km}$ west of the modern city of Seville. Especially on two neighbouring areas in the Northern part of Valencina we undertook geomagnetic and an archaeological surveys and manual drillings of the anomalies registered. To sum up, the geo-magnetic survey in the "Parcela Municipal del Cerro de la Cabeza" and the Southern part of the area "Cerro Mármol" delivered a great number of circular and oval anomalies, which probably represent pits, silos and houses with sunken floors. On the other hand, several linear anomalies were documented. The manual drillings allow us to define the majority of these structures as ditches. Maybe they are related with three ditched enclosures, which should have been operative in different moments. The ceramic material found during the archaeological survey speaks for a Chalcolithic dating of the majority of the documented structures.
\end{abstract}

Otto-Friedrich-Universität, Am Kranen 14, D-96047 Bamberg, Correo-e: thomasxsch@ono.com.

**** Lehrstuhl für Vor- und Frühgeschichtliche Archäologie, Julius-Maximilians-Universität Würzburg, Residenzplatz 2, Tor A, D-97070 Würzburg, Correo-e: frank.falkenstein@uni-wuerzburg.de; thomas.link@uni-wuerzburg.de 
Palabras clave: Calcolítico. Estuario del Guadalquivir. Recintos de Fosos. Prospección geo-magnética. Prospección de superficie. Perforaciones manuales.

\section{INTRODUCCIÓN}

Pocos kilómetros al oeste del centro de la actual Sevilla, se encuentra en el municipio de Valencina de la Concepción un importante yacimiento calcolítico (Schuhmacher et al., en prensa). Se localiza en el borde nororiental de la meseta del Aljarafe, que se eleva unos $150 \mathrm{~m}$ sobre el valle del Guadalquivir, en la margen derecha u oeste del río (Costa Caramé et al. 2010, García Sanjuán 2013, Vargas 2013a). Según los actuales datos, el yacimiento prehistórico cubre un área de poblado de $235^{\prime} 6$ ha y una necrópolis contemporánea de 233'2 ha (Vargas 2003 y 2004, Cruz-Auñón y Mejías 2013) (fig. 1). El área poblacional se encuentra en su mayor parte por debajo del actual núcleo de Valencina de la Concepción, lo que ha dificultado una investigación arqueológica sistemática que inevitablemente se ha sustituido por numerosas, y no siempre rentables científicamente, excavaciones de urgencia y seguimientos de obra. Al norte del núcleo urbano de Valencina se extiende el área de población prehistórica por encima de varios espolones hasta alcanzar el borde de la meseta, que cae con un gran desnivel respecto a la llanura inmediata (fig. 2). El área de necrópolis que se encuentra al sur y este se extiende sobre todo en espacios de uso agrícola y más allá del límite municipal de Valencina de la Concepción, hasta el vecino municipio de Castilleja de Guzmán. Pero ya Costa Caramé et al. (2010, García Sanjuán 2013, García Sanjuán y Murillo Barroso 2013) llaman la atención sobre que la idea de una diferenciación estricta entre área poblacional y de necrópolis no es cierta, porque restos humanos se han encontrado en toda el área poblacional. Mientras los enterramientos en el sur se encuentran parcialmente en construcciones funerarias de carácter megalítico (tumbas de tholos con corredor), en el área norte se han documentado restos humanos en estructuras domésticas como fosas o silos. En el suroeste del área poblacional además encontramos enterramientos en hipogeos, lo que llevó a Cruz-Auñón y Mejías (2013) a extender el área de necrópolis hasta este sector y por lo tanto reducir más el área de actividades domésticas.

Las investigaciones arqueológicas en Valencina empezaron con el descubrimiento de la tumba colectiva de La Pastora en 1860 (Belén 1991; Mederos 2000;
Key words: Chalcolithic. Guadalquivir estuary. Ditched enclosures. Geo-magnetic survey. Archaeological survey. Manual Drillings.

Ruiz Moreno 2013). Hasta mediados del siglo XX los nuevos hallazgos se referían exclusivamente al área de necrópolis, como por ejemplo los de las tumbas de Matarrubilla y Ontiveros, tan solo a partir de los años 70 del siglo XX el área de poblado comenzó a despertar el interés de la investigación. Así en el año 1971 se efectuó la primera intervención en el área del poblado en la zona conocida como La Perrera, que no se encuentra lejos de la parcela del Cerro de la Cabeza, que es el objeto principal de las prospecciones que aquí presentamos (Ruiz Mata 1975a, 1975b y 1983; Vargas 2004). En dos pequeños cortes se recuperó por primera vez información estratigráfica y se pudo diferenciar un estrato con cerámica campaniforme de otro inferior calcolítico, pero sin campaniforme. Las excavaciones en esta zona siguieron en el año 1975, abriendo cuatro cortes en diferentes parcelas donde se iba a construir (Fernández Gómez y Oliva 1985; Fernández Gómez 2013). En el corte A se localizó un foso con perfil en V con una profundidad de $7 \mathrm{~m}$. A esto hay que añadir diferentes hogares y un nivel de ocupación que consiste en un suelo de piedras sobre el cual se encontraron fragmentos campaniformes. En el corte $\mathrm{C}$ se descubrió otro foso con un perfil en $\mathrm{V}$ y una profundidad de 1'30 m y además tres fosas que se comunicaban entre ellas y un horno excavado en el subsuelo. Además, los excavadores mencionan una estructura con perfil troncocónico en el corte $\mathrm{Cb}$, que también interpretan como foso, pero como Vargas (2004: catálogo 26-32) indica, esta estructura por sus características deberíamos compararla con una estructura habitacional, caso de un fondo de cabaña. Finalmente, en el corte $\mathrm{C}$ se constataron dos fosos yuxtapuestos, dos silos cronológicamente más recientes y un posible fondo de cabaña.

Para la zona más próxima de la parcela municipal del Cerro de la Cabeza, podemos mencionar las actividades del Museo Arqueológico de Sevilla en 1975-76. Estos trabajos se efectuaron al noreste de esta parcela, en el margen occidental de la carretera que lleva de Valencina de la Concepción a Santiponce (Fernández Gómez y Ruiz Mata 1978; Fernández Gómez y Oliva 1980 y 1986, Fernández Gómez 2013). En concreto, en el año 1975 se descubrió una parte de una cámara funeraria circular. Esta estaba excavada en el subsuelo y las paredes cubiertas con losas de pizarra. Se encontraron 


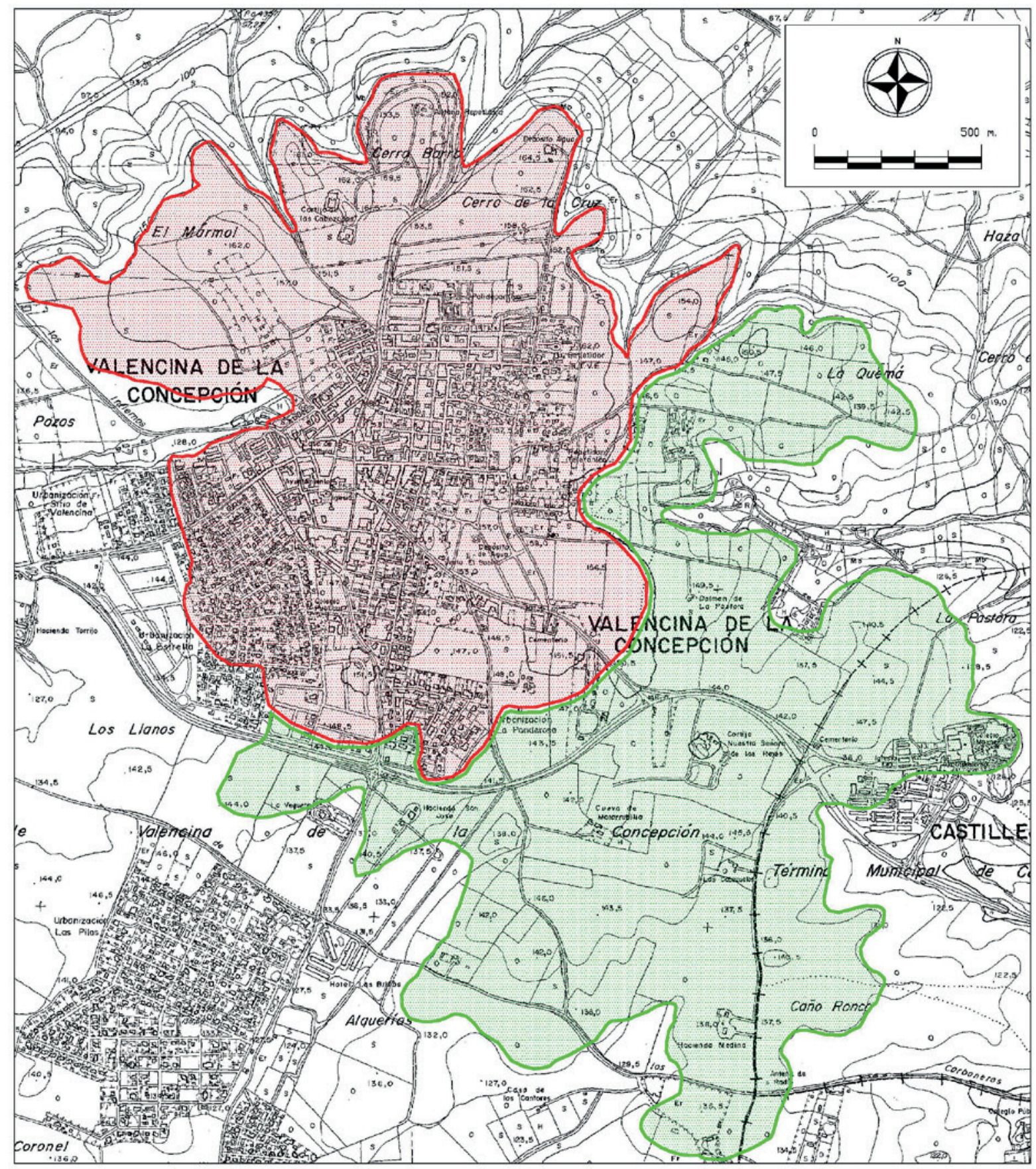

Figura 1. Valencina de la Concepción. Propuesta de la extensión del área del poblado calcolítico (en rojo) y del de la necrópolis (en verde) en los municipios de Valencina de la Concepción y Castilleja de Guzmán (Provincia de Sevilla, Andalucía). J. M. Vargas (Valencina de la Concepción).

materiales del Calcolítico y del Bronce Final. En el año siguiente, se estudió una superficie de 1 ha que también se encuentra al occidente de la carretera hacia
Santiponce (fig. 3). Se documentaron dos largos fosos paralelos sobre una longitud de unos $100 \mathrm{~m}$. Su profundidad estaba entre 2 y $3 \mathrm{~m}$ y tenían una anchura de $4 \mathrm{~m}$. 


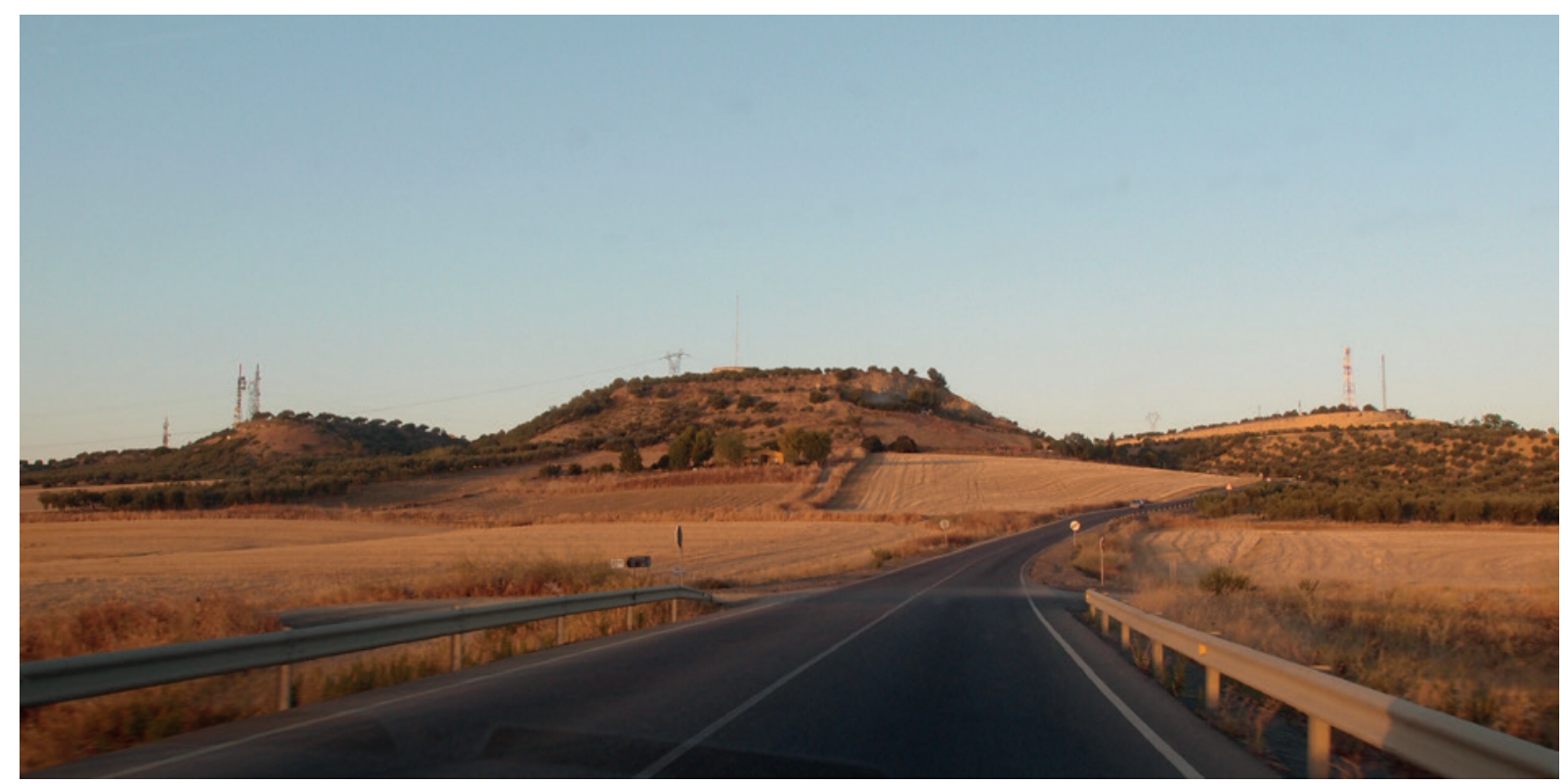

Figura 2. Vista de la parte norte de Valencina desde Santiponce. Foto de Th. Link.

A ambos lados y entre los dos fosos se localizaron una multitud de fosas. Al exterior de la zona limitada por los fosos, se localizaron varios pozos con un diámetro de un metro, que en algunos casos alcanzaron la profundidad de $10 \mathrm{~m}$. Inmediatamente al lado de la carretera se excavó un fondo de cabaña rectangular con un ábside oval y una entrada cuadrada, que estaba parcialmente excavado en el subsuelo (Murillo Díaz et al. 2006). Pero en este caso, los materiales recogidos en esta zona hacen pensar en una datación post-calcolítica, dentro del segundo milenio a.C.

También más al este de la "Parcela Municipal del Cerro de la Cabeza", se documentó durante una excavación de urgencia efectuada en 1985, a raíz de la construcción del Polideportivo Municipal, otro foso con un perfil en $\mathrm{V}$ y una profundidad de $4 \mathrm{~m}$, un pozo, un muro de adobe y partes de un muro de piedras (Murillo Díaz et al. 2006).

En el año 1990 se desarrolló una prospección geomagnética en la llamada Estacada Larga, situada al este del Cerro de la Cabeza (Vargas 2004: 115s). Como resultado de estos resultados se efectuó en 1995 un corte que englobó la mayoría de las anomalías documentadas. También en esta ocasión se localizó un foso que tenía en superficie una anchura de $4 \mathrm{~m}$ y una profundidad de 3'60 m y dos posibles fosas. Vargas (2004: 115) concluyó, a raíz de la documentación gráfica de esta excavación, que el foso originariamente tenía que haber tenido una anchura de $8 \mathrm{~m}$ pero que en la excavación solamente se documentó la mitad. En este caso podría corresponder a otro foso descubierto en 1995, con una anchura de $7 \mathrm{~m}$ y una profundidad de $4 \mathrm{~m}$. Este último foso fue descubierto con motivo de la apertura de una zanja para la acometida de aguas en la limítrofe Urbanización Mirador de Itálica. Se realizó un seguimiento de obra de esta zanja, de las cimentaciones de las casas vecinas y de un perfil de la carretera de Valencina a Santiponce y en consecuencia, se efectuaron cuatro cortes (Cruz-Auñón y Arteaga 1999). El mencionado foso apareció cerca del final occidental de esta zanja de conducción de agua en el corte A. Para determinar la orientación del foso se abrió el corte $\mathrm{C}$ al norte del corte A, donde se identificó el mismo foso que, por lo tanto, iba en dirección norte. Según los excavadores se pudo documentar el mismo foso a unos $300 \mathrm{~m}$ al norte del corte $\mathrm{C}$, en el perfil de la carretera. Además se localizaron 28 fosas.

Entre agosto de 2008 y enero de 2009, antes de la construcción del Pabellón Cubierto, se hizo una excavación arqueológica (Ortega 2013). Se pudieron documentar 29 fosas circulares en planta que representan, por lo menos, tres fases de uso sucesivo, pero pertenecientes las tres al Calcolítico. Además se excavó una estructura oval de 4 x 3'50 m con un acceso en forma de escalera, que se interpretó como un lugar de almacenaje de cereal. También se excavó una estructura de planta irregular, con una compartimentación trasversal en la parte sur y restos de otra en la parte septentrional. 


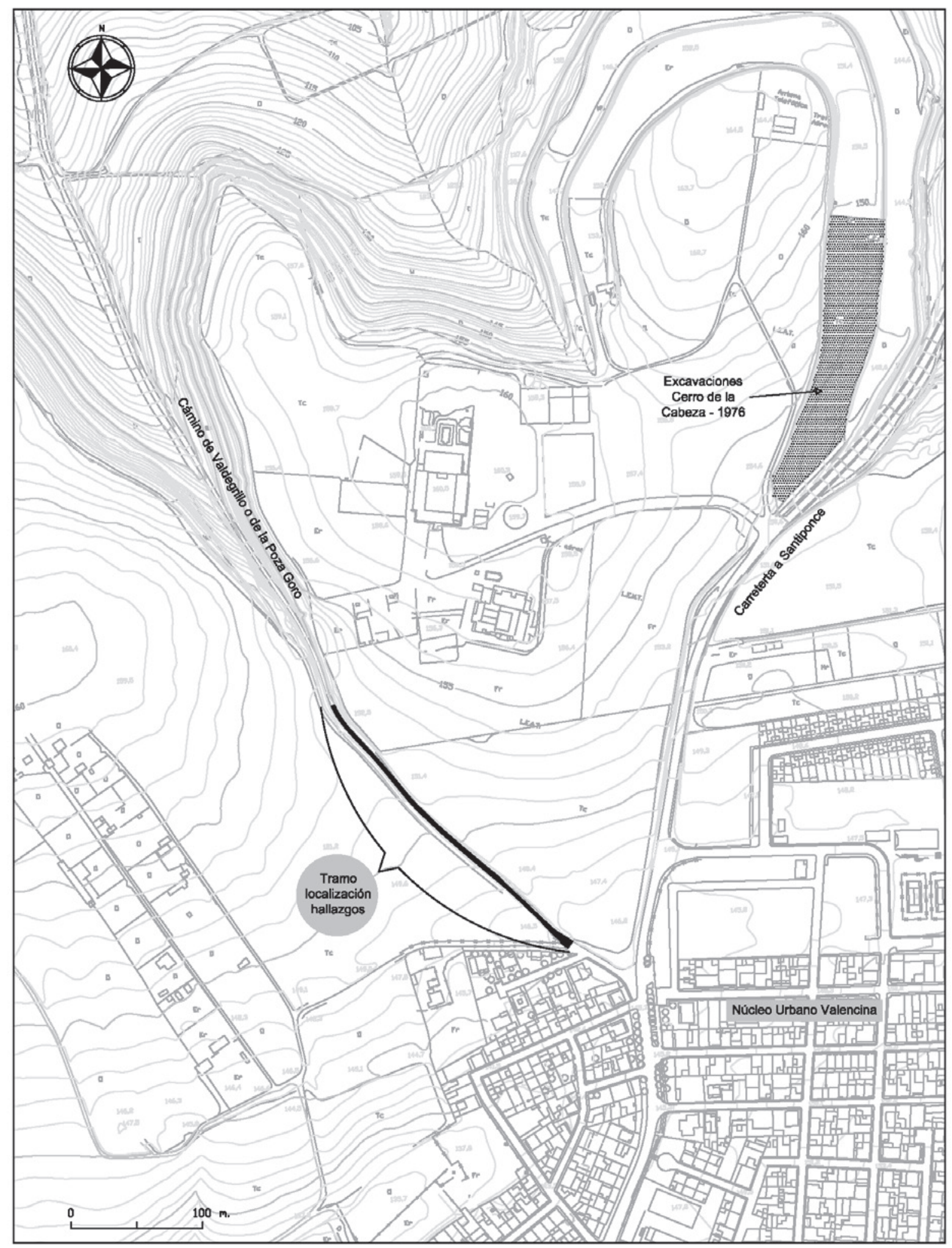

Figura 3. Valencina de la Concepción. Mapa topográfico de la parcela Cerro de la Cabeza con la situación del área excavada en 1976 en el "Cerro de la Cabeza" y el perfil documentado en 2012 y 2013 a lo largo del "Camino de Valdegrillo". 
Tanto el relleno de esa estructura como el estrato que la cubrió contenían cerámica campaniforme. Finalmente, se descubrió una estructura con planta oval, que contenía materiales protohistóricos, entre ellos un plato fenicio de engobe rojo y una fíbula de bronce de doble resorte. Además, se identificaron 16 agujeros de poste, 35 zanjas irregulares y 9 estructuras habitacionales o de producción, aparte de otras estructuras irregulares.

Delimitada por un lado por la Estacada Larga, por el este la urbanización de Itálica y al sur la urbanización de La Gallega, se encuentra la parcela de "Zona verde entre calles Vauvert y Carlos Cano". En una intervención en la urbanización La Gallega entre diciembre de 1990 y junio de 1991, antes de la construcción de las casas, se localizaron 23 estructuras (Martín Espinosa y Ruiz Moreno 1992). Se trata, sobre todo de fosas, que pertenecen a dos fases diferentes, probablemente Calcolítico Precampaniforme y Campaniforme.

En la urbanización Mirador de Itálica se efectuó en 1994, antes del comienzo de las obras, una prospección geomagnética que reveló una serie de anomalías (Ruiz Moreno 1999). Dos de ellas se interpretaron como hogares y la última como una zanja poco profunda de $6 \mathrm{~m}$ de largo y una anchura de 0'50 m.

Resumiendo, las estructuras hasta ahora documentadas se limitan a varias docenas de fosas en diferentes parcelas no contiguas. En la mayoría de los casos se las interpreta de manera genérica como basureros, fosas de almacenaje o silos. En algunos pocos casos se documentaron fosas más grandes, menos profundas e irregulares, que se interpretaban como posibles fondos de cabaña. Además encontramos segmentos cortos de estructuras lineales de anchura, profundidad y orientación variable, que se interpretan como partes de recintos que delimitan áreas de hábitat. Pero en realidad los segmentos de foso hasta ahora documentados son demasiado cortos y se distribuyen por un área demasiado grande para poder situar los espacios habitacionales que supuestamente delimitan y la superficie real que circunscriben. Dataciones absolutas faltan en la mayor parte de estas estructuras de hábitat, por eso en realidad no tenemos una idea precisa sobre el tamaño, la estructura interna y la evolución de los espacios de hábitat propuestos.

Por otro lado, según las intervenciones puntuales y las prospecciones arqueológicas hasta ahora efectuadas, materiales y estructuras calcolíticas se encuentran en toda la supuesta área poblacional. Se calcula la superficie total de hábitat en unas 230 ha, por lo que superaría con creces a todos los restantes poblados calcolíticos de la península ibérica, e incluso del Mediterráneo
Occidental. Estos en pocos casos superan una superficie de 20 ha (San Blas 30 ha, Polideportivo de Martos 40 ha, Porto Torrão 75-100 ha, La Pijotilla 80 ha, Marroquíes Bajos 113 ha) (Vargas 2013: tabla 3; Márquez y Jiménez 2010: 138). Al mismo tiempo, Nocete et alii (2008: 728) calcularon a raíz de sus excavaciones en el denominado sector metalúrgico, la producción de más de una tonelada de metal, lo que también superaría con creces la producción metalúrgica de otros poblados contemporáneos. García Sanjuán (2013: 43) critica este cálculo realizado a partir del número de crisoles encontrados, ya que el peso total de los objetos de cobre hasta ahora documentados en Valencina supone menos de $10 \mathrm{~kg}$.

Esto contrasta con la información que disponemos para la necrópolis (García Sanjuán 2013, García Sanjuán et al. 2013, Cruz-Auñón y Mejías 2013, Mora et al. 2013, Fernández Flores y Aycart 2013). Así, las tumbas de Matarrubilla, La Pastora, Montelirio y la tumba 10.042-10.049 del sector PP4 de Montelirio están entre los monumentos funerarios conocidos más grandes del Calcolítico de la península ibérica. El ajuar de los enterramientos respectivos habla a favor de una compleja organización social en la que algunos personajes tuvieron un estatus especial demostrando su prestigio y poder a través de objetos fabricados con materias primas exóticas como marfil africano y asiático, huevo de avestruz y ámbar. Al mismo tiempo, en algunos casos se trata de inhumaciones individualizadas, lo que les separa de los habituales enterramientos colectivos típicos del Calcolítico, y podría indicar el comienzo de una sociedad estratificada. Por eso sería de gran interés investigar cómo se manifiesta este comienzo de la complejidad documentado en las tumbas en el espacio habitacional.

\section{OBJETIVOS Y DESARROLLO DE LA PROSPECCIÓN}

Aunque en los últimos decenios se han efectuado numerosas excavaciones de urgencia y seguimientos de obras en el núcleo urbano de Valencina, la información que tenemos del espacio habitual es muy dispersa, fragmentaria y de interés variable (García Sanjuán 2013). Las lagunas en la información han incluso llevado a poner en duda el carácter poblacional de Valencina. Así, García Sanjuán (2013: 35) formula la cuestión de si Valencina podría ser un sitio de reunión temporal para la celebración de fiestas religiosas y ritos de enterramiento, preguntándose “Es Valencina un 'poblado’ (...)? ¿Cómo 
de permanente era la ocupación de Valencina? ¿Es Valencina un lugar utilizado periódicamente (...) para su agregación ocasional con fines diversos entre las que la conmemoración funeraria y los ritos religiosos habrían tenido un indiscutible papel central?".

Para obtener datos concisos acerca de la estructura interna y de la evolución de hábitat de Valencina de la Concepción, nos parece imprescindible investigar de manera intensiva grandes extensiones de hábitat. Para esto son adecuadas las áreas situadas al extremo norte de la población actualmente en uso agrícola de cereal $\mathrm{u}$ olivar. Estas investigaciones prometen ofrecer datos adecuados acerca de su extensión, dinámica interna y límites. Al mismo tiempo permiten resolver cuestiones sobre las estructuras de hábitat y su densidad, las diferencias entre área de habitación y área de producción, y de la sucesión de fases constructivas. Hay que contar que a lo largo del Calcolítico debieron producirse cambios en la superficie habitada, ampliaciones o reducciones del espacio de habitación y de producción.

En una primera campaña de prospección en 2014 queríamos evaluar el potencial de investigación de las parcelas agrícolas de la parte septentrional del poblado, para desarrollar una estrategia de investigación para un futuro proyecto de intervenciones sistemáticas. Se pretendía resolver qué tipo de estructuras domésticas se conservaban y el estado de preservación y qué metodología de trabajo sería más adecuada de aplicar. Además, queríamos obtener información acerca de la posición cronológica de las estructuras identificadas en la prospección geofísica.

Para alcanzar estas metas utilizamos una prospección geomagnética, recogida de material de superficie y perforaciones manuales. Cada uno de estos métodos tan sólo refleja parte de la situación real del yacimiento, pero la interconexión de las anomalías magnéticas con la distribución del material de superficie y las perforaciones manuales permite conocer el registro arqueológico conservado de una manera mucho más precisa y complementaria. La geomagnética identifica las estructuras, los sondeos manuales precisan la profundidad real y su naturaleza y el material de superficie, sobre todo en un yacimiento como Valencina, de ocupación principalmente calcolítica, permite dar una orientación cronológica bastante aproximada.

Un complemento importante para las prospecciones fue la documentación arqueológica de un perfil a lo largo de $250 \mathrm{~m}$ del Camino de Valdegrillo, que limita la parcela municipal del Cerro de la Cabeza en el suroeste, realizada previamente en el año 201213 (Vargas 2013b; Schuhmacher et al. en prensa). Se documentó un total de 21 estructuras. Por lo menos dos de estas estructuras, y tal vez una tercera, se caracterizaron por su perfil como fosos, definiendo las demás estructuras como fosas, silos o fondos de cabañas.

Los trabajos, con una duración de 2 semanas, se efectuaron en el marco de un acuerdo de cooperación entre el municipio de Valencina de la Concepción, la fundación de la Universidad Autónoma de Madrid (FUAM) y la Universidad Julius-Maximilian de Würzburg (JMU), además de una cooperación permanente con la Casa de Cultura-Museo Municipal de Valencina de la Concepción. La financiación fue aportada por la Bayerische Forschungsallianz y la Facultad de Filosofía de la Universidad de Würzburg y su fondo de investigación.

En base al acuerdo de cooperación, el Ayuntamiento de Valencina de la Concepción nos dio autorización de acceso a las parcelas municipales. Se trata de la "Parcela municipal del Cerro de la Cabeza", la "Zona verde entre calles Vauvert y Carlos Cano", el "Parque de La Gallega" y la "Parcela municipal La PastoraEl Cuervo" (fig. 4). Por diversas razones nos centramos en las dos primeras parcelas. Durante los trabajos y en atención a los interesantes resultados que se estaban mostrando tuvimos la oportunidad de extender las prospecciones hacia la ladera del Cerro del Mármol, la limítrofe parcela oeste, gracias a la amable autorización recibida de sus propietarios. La campaña de prospección se efectuó del 26 de agosto al 9 de septiembre de 2014. El equipo de trabajo estaba compuesto por los autores y dos estudiantes de la Universidad de Würzburg, Franz Bechtold y Philipp Schinkel.

\section{EL PERFIL DEL CAMINO DE VALDEGRILLO}

Ya entre diciembre de 2012 y enero de 2013, Juan Manuel Vargas Jiménez documentó a lo largo del límite suroccidental de la parcela municipal del Cerro de la Cabeza un perfil de $250 \mathrm{~m}$ en el Camino de Valdegrillo (Vargas 2013b) (figs. 5-6). El perfil que tenía una altura aproximada de $2 \mathrm{~m}$ y era más o menos vertical, fue primero perfilado y luego se documentaron con dibujos y fotografías las estructuras visibles. Se pudieron documentar estructuras prehistóricas, en su mayoría fosas, pero también algunas zanjas, todas excavadas en el suelo virgen y cubiertas por sedimento arqueológico. Durante las prospecciones de 2014, documentamos las estructuras UC 8 a UC 21 en el sector de la "Parcela municipal del Cerro de la Cabeza" de manera 


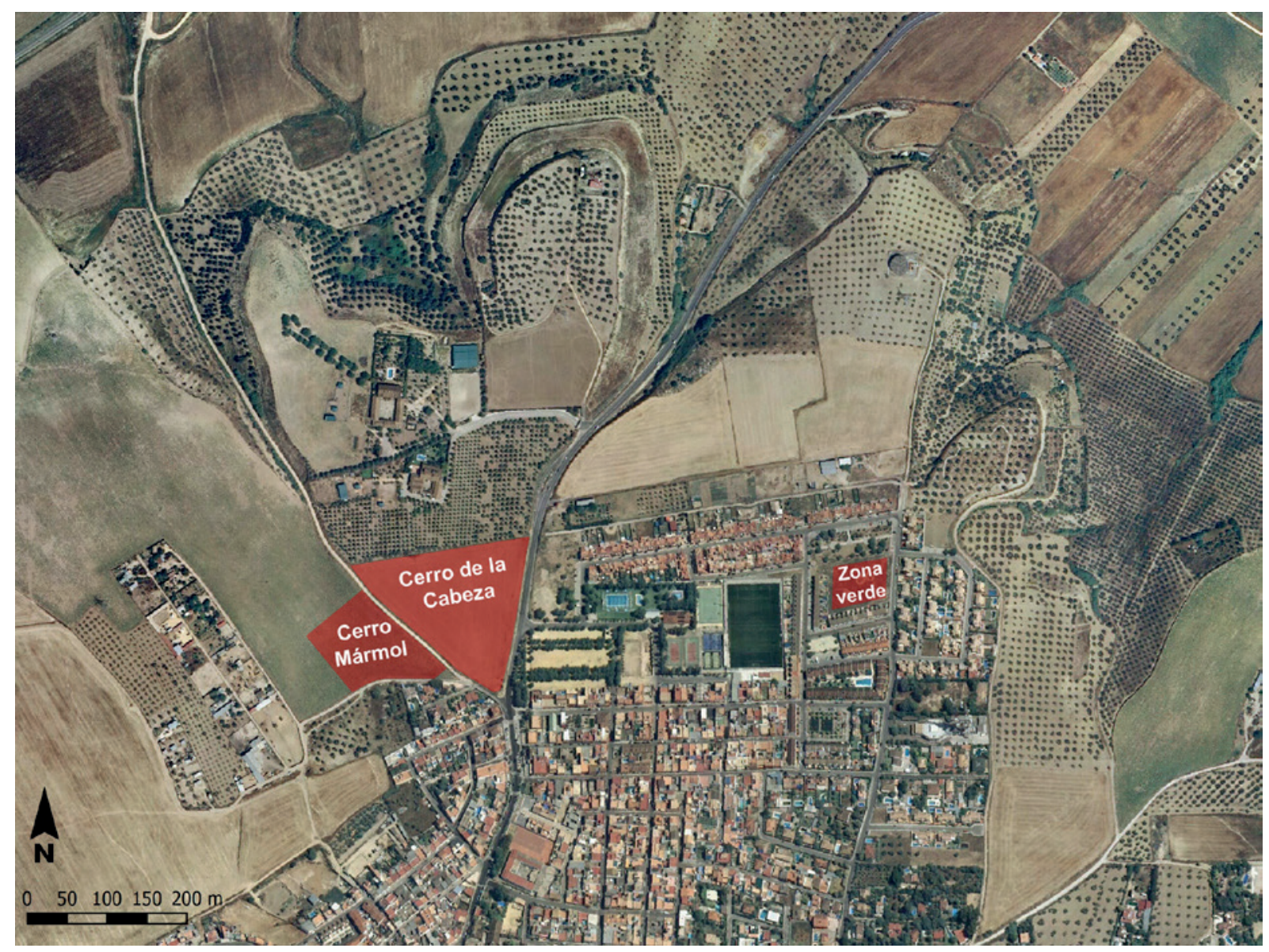

Figura 4. Valencina de la Concepción. Situación de las superficies prospectadas en 2014: "Parcela municipal del Cerro de la Cabeza"; "Zona verde entre calles Vauvert y Carlos Cano" y "Cerro Mármol".

Orthophoto: (C) Instituto Geográfico Nacional de España.

tridimensional con el RTK-GPS-Rover, para poder correlacionarlas con las documentadas en la prospección geomagnética (figs. 5 y 9).

Se pueden diferenciar dos sectores con una mayor acumulación de estructuras arqueológicas. Así, en la parte septentrional, y por lo tanto más allá de la parcela prospectada en 2014, se documentaron las estructuras UC1-UC7, que consisten en estructuras excavadas en el subsuelo con base plana o ligeramente cóncava -UC5-. Las paredes son verticales o ligeramente convergentes -UC3-. Los anchos varían entre 1'50 y 7’30 m-UC5-. Sus profundidades varían entre 0'52 y $1 ’ 28 \mathrm{~m}$. Mientras la mayoría de las estructuras están cubiertas por un sedimento de $0^{\prime} 60-0^{\prime} 90 \mathrm{~m}$, se encuentra la fosa UC1, la más septentrional, a 1'25 m. por debajo de la superficie actual. En su mayor parte, podría tratarse de fosas de almacenaje-UC3-o de fosas domésticas con otra funcionalidad. En el caso de UC5, podría tratarse por sus dimensiones de un ancho de $7 \mathrm{~m}$, profundidad de 1'28 m y su base cóncava, de un foso (Vargas 2013b: 7, fig. 2, lám. 2).

A este sector septentrional sigue un sector con una longitud de $20 \mathrm{~m}$ sin estructuras visibles, pero es en este sector donde el límite superior del subsuelo natural tiene mayor profundidad, en contraposición a la actual superficie. Esta depresión está rellena de sedimento arqueológico, sin que puedan diferenciarse estructuras individualizables, pero contiene cerámica y útiles líticos.

Este estrato arqueológico se extiende por toda la zona de la "Parcela municipal del Cerro de la Cabeza" y se sobrepone con un grosor entre 0'45-0' $65 \mathrm{~m}$ por encima de las estructuras UC8-UC13. Además, este sector parece subdividirse en dos estratos arqueológicos. Así, mientras el superior cubre el silo o fosa UC8, al mismo tiempo es el relleno superior del foso o zanja 


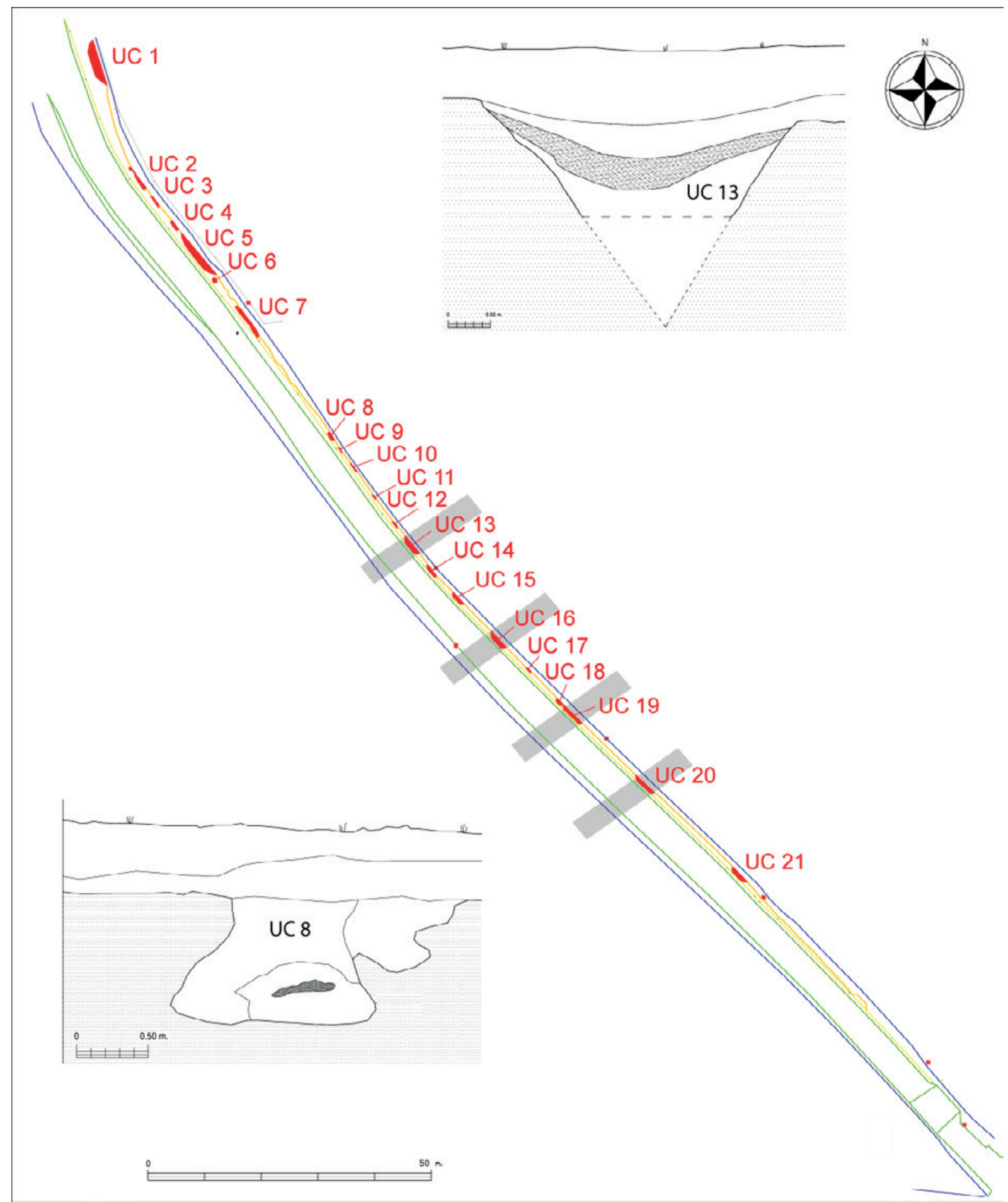

Figura 5. Valencina de la Concepción. El perfil del "Camino de Valdegrillo" con las estructuras documentadas y los dibujos de los perfiles de las unidades UC 8 (fosa troncocónica) y UC 13 (foso). J. M. Vargas (Valencina de la Concepción). 


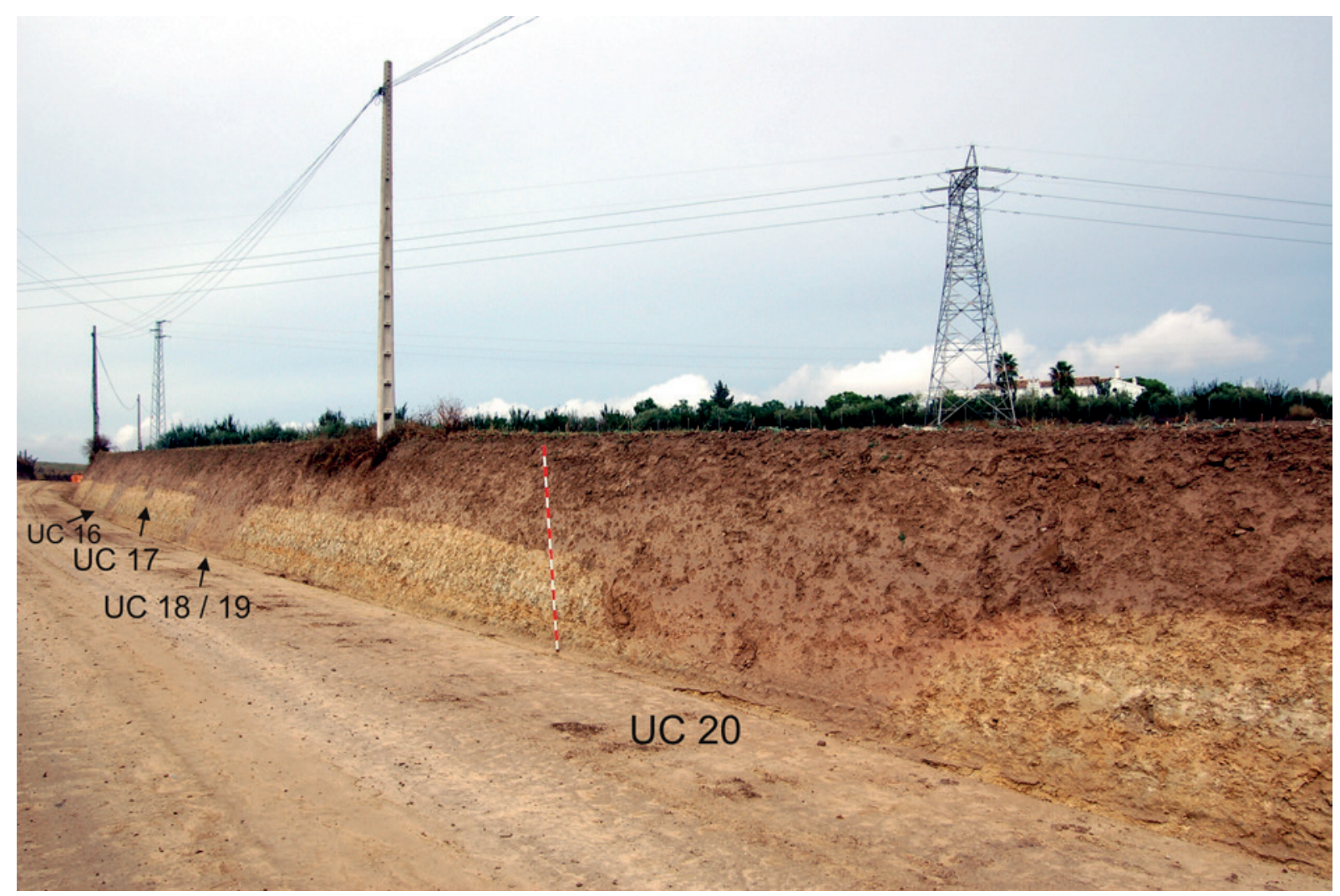

Figura 6. Valencina de la Concepción. Vista del perfil en el "Camino de Valdegrillo". En la sección del perfil se pueden observar las UC16 a la UC20. Foto de J. M. Vargas (Valencina de la Concepción).

UC13. De eso podemos concluir que la sedimentación del estrato arqueológico comenzó cuando el foso UC13 ya estaba parcialmente relleno (fig. 5 -UC8 y UC13-).

Más al sur, estos dos estratos de la sedimentación, con una consistencia arcillosa y con un grosor entre 0'80 y 1'10 m, se extienden sobre unos $100 \mathrm{~m}$ hasta el comienzo del Camino del Valdegrillo. A partir de la documentación fotográfica podemos hacer también algunas inferencias sobre la relación de las estructuras y su sedimentación. Así, el estrato inferior cubre la estructura UC15, mientras parece que se haya excavado la estructura UC18-19 a partir del límite superior de este estrato inferior, sugiriendo quizás que UC18-19 es más reciente que $\mathrm{UC15}$. Al mismo tiempo, el estrato inferior del sedimento arqueológico conforma el relleno superior del foso o zanja UC20, de lo que podemos sacar algunas conclusiones estratigráficas: el estrato superior del sedimento arqueológico, con un grosor de 0'50-0'60 m es más reciente que todas las estructuras documentadas y se trata probablemente de un estrato postdeposicional de erosión. El estrato inferior conforma un estrato arqueológico que se depositó durante la ocupación calcolítica del yacimiento, mientras el foso o zanja UC20 es contemporáneo al comienzo de la deposición del estrato arqueológico.

En el perfil que delimita la "Parcela municipal del Cerro de la Cabeza" se han encontrado silos de perfil troncocónico con un ancho de base bastante homogéneo entre 1'20-1'40 m, y unas profundidades conservadas entre 0'35-1 m (UC8, UC9, UC12 y UC17). Por otro lado, aparecen fosas con una base más cóncava que, aunque muestran profundidades parecidas entre 0’35-1 m, sus anchuras, entre 2' 15 y 3'90 m, son bastante más grandes que las de los silos (UC10, UC14, UC15 y UC21). En el caso de las estructuras UC10, UC14 y UC15, por sus dimensiones y su forma debería tratarse de fondos de cabaña. Y en el caso de UC19 y UC21, con unos fondos cóncavos, una profundidad de $1 \mathrm{~m}$ y más de $3 \mathrm{~m}$ de anchura debería tratarse de fosos. Así, UC19 lo podemos relacionar con el foso 6 y UC21 con el foso 19 del magnetograma de la prospección de 2014 (figs. 5 y 9).

Pero en el perfil también vemos otros fosos prehistóricos, así el foso UC13, con una anchura de $4 \mathrm{~m} \mathrm{y}$ un perfil en $\mathrm{V}$, completando el perfil del foso podemos 


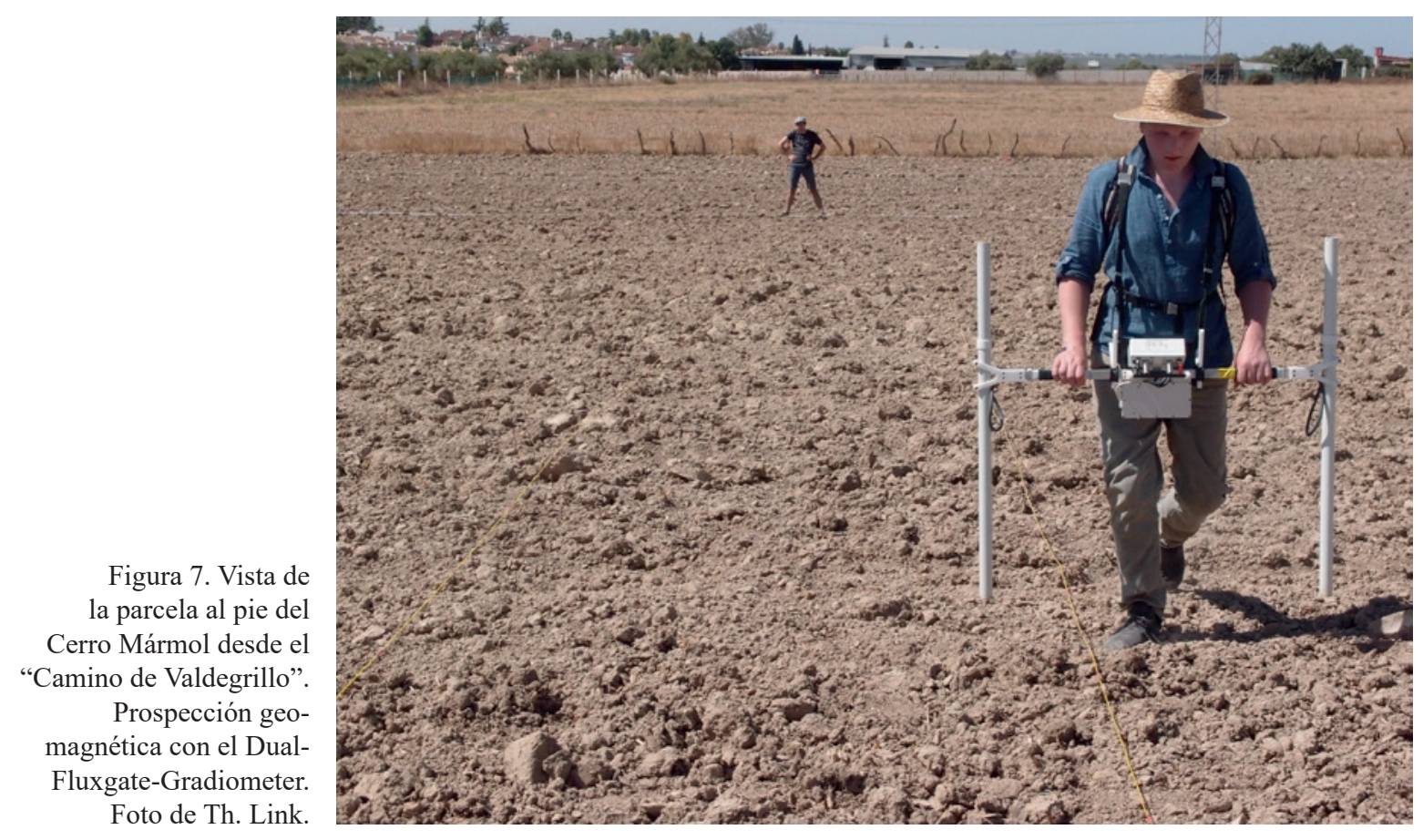

calcular una profundidad original de $2^{\prime} 70 \mathrm{~m}$. El foso UC13 corresponde con el foso 24 del magnetograma (fig. 9). Los perfiles de los fosos UC18 y UC19 que se encuentran muy próximos entre sí, tienen una profundidad de poco más de $1 \mathrm{~m}$ (1'18 y 1'04 m) y una anchura de 2'04-3'60 m. Probablemente representen dos fases sucesivas de un foso y se pueden correlacionar con el foso 6 del magnetograma (figs. 5 y 9).

Estratigráficamente más antiguo que los fosos UC18/19 es probablemente el foso UC20, que se encuentra unos $10 \mathrm{~m}$ más al Sur, tiene una anchura de 4'63 $\mathrm{m}$ y un perfil en $\mathrm{V}$ y una profundidad original de más de $3 \mathrm{~m}$. Este foso corresponde con el foso $7 \mathrm{del}$ magnetograma (Vargas 2013b: 8-13, fig. 3, lám. 2-3) (figs. 5, 8 y 9).

\section{LA PROSPECCIÓN GEOMAGNÉTICA}

La prospección geomagnética no destructiva se considera hoy un método estándar de la arqueología de campo. Según el tipo de suelo, las estructuras arqueológicas conservadas y el estado de la superficie, se puede aplicar de manera eficiente y en grandes áreas. En los últimos años se habían efectuado dos prospecciones geomagnéticas en extensas áreas de la parte sureste y necrópolis del asentamiento de Valencina (Vargas Jiménez et al. 2012; Wheatley et al. 2012).
La retícula de análisis era de cuadrados de 30 x 30 $\mathrm{m}$. Se prospectaba en líneas paralelas de manera sucesiva. Los puntos de referencia se pusieron con la ayuda de un RTK-GPS-Rover, en coordenadas UTM con una exactitud de aproximadamente 2 o $3 \mathrm{~cm}$. El magnetómetro utilizado era un Dual-Fluxgate-Gradiometer del tipo Bartington-Grad 601-2 con una sensibilidad de 0'03 nT (fig. 7). La densidad de los puntos de medición en dirección sureste-noroeste (a lo largo de las líneas de guía), era de $12^{\prime} 5 \mathrm{~cm}$. En dirección norestesuroeste (correspondiente a la distancia elegida de las líneas guía), era de 0'50 m. Durante el tratamiento de los datos se interpolaba la intensidad de puntos de medición en 12'5 x $25 \mathrm{~cm}$.

Se han prospectado completamente la "Parcela municipal de La Cabeza" y la "Zona verde entre calles Vauvert y Carlos Cano" (fig. 4). Por problemas de tiempo y una ampliación de la prospección a la parcela de Cerro Mármol, tuvimos que posponer la medición de las parcelas "Parque de la Gallega" y "Parcela El Cuervo-Pastora", para una futura campaña.

La prospección de la "Zona verde entre calles Vauvert y Carlos Cano" no dio ningún resultado significativo, pues lo que se obtuvo fue una imagen muy distorsionada por las interferencias magnéticas. Eso fue producido por objetos metálicos de pequeño y medio tamaño, como chapas de botella, latas, clavos, etc. Aunque se intentó limpiar la zona de objetos 


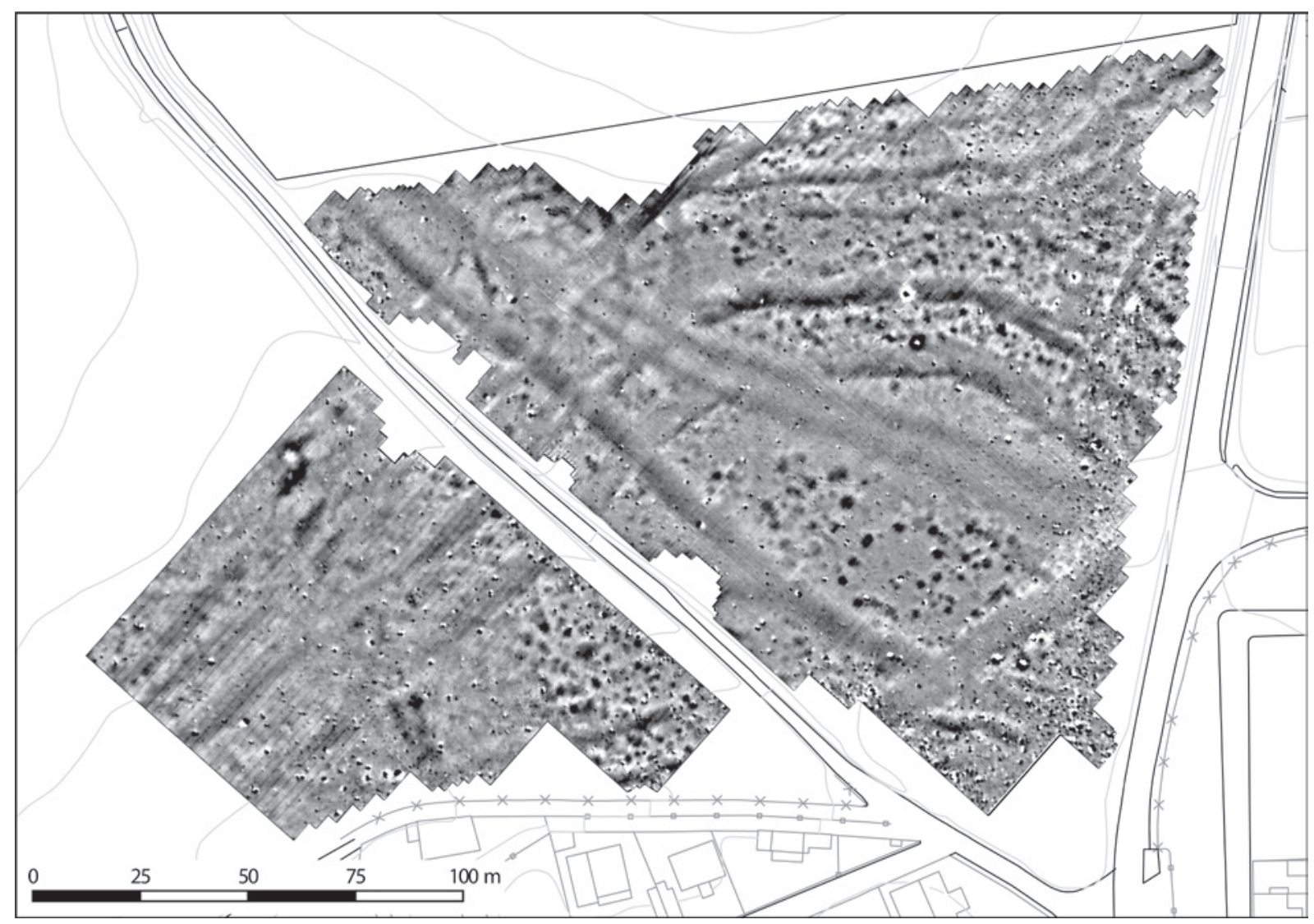

Figura 8. Magnetograma de la prospección geomagnética en las parcelas "Parcela municipal del Cerro de la Cabeza" (derecha) y "Cerro Mármol" (izquierda). Se aprecian (como manchas oscuras) de manera clara estructuras lineales como fosos y caminos y clusters de fosas en forma de anomalías positivas. Dual-Fluxgate-Gradiometer Bartington Grad 601-2, dinámica -8 nT (blanco) hasta $+8 \mathrm{nT}$ (oscuro) en 256 tonos de gris, densidad de puntos de medición 12,5 x $50 \mathrm{~cm}$ (interpolado a $12,5 \times 25 \mathrm{~cm}$ ), Retícula de 30 m. Lehrstuhl für Vor- und Frühgeschichtliche Archäologie, JMU Würzburg. Mapa base: (C Instituto Geográfico Nacional de España.

metálicos visibles superficialmente, parece que todavía se encuentran metales en el sedimento del terreno, ligeramente enterrados. Por lo tanto, una prospección magnética en la "Zona verde de las calles Vauvert y Carlos Cano" solamente podría tener éxito retirando esta capa superficial de unos 0'10 o 0’20 m de manera mecánica para evitar las interferencias magnéticas y eliminar estos objetos metálicos.

Pudimos prospectar por completo la "Parcela municipal del Cerro de la Cabeza", que tiene una superficie de 2 ha. Aquí tan solo encontramos interferencias importantes en el extremo sur de la parcela y a lo largo de los bordes. Un poste de alta tensión y algunas líneas de electricidad tan solo producían interferencias alrededor de los postes y creaban pequeñas lagunas en el magnetómetro. Por la alta densidad de las anomalías del Cerro de la Cabeza (figs. 8-9), nos pareció muy conveniente prospectar también la parcela inmediata al oeste, principalmente para resolver si había continuidad de las estructuras lineales en la parcela vecina. Después de obtener el permiso del propietario, D. Joaquín González, y el visto bueno pertinente del arqueólogo provincial, José Manuel Rodríguez Hidalgo, se amplió la prospección geomagnética a la parte Sur de la parcela Cerro Mármol, prospectando otras 0'9 ha adicionales.

La prospección geomagnética de la parcela municipal del Cerro de la Cabeza y de la parte sur del Cerro Mármol aportó una gran cantidad de anomalías que podemos clasificar en dos tipos básicos (figs. 8-9). A un lado hay anomalías circulares o amorfas, con diámetros de pocos metros, y por otro lado anomalías lineales que pueden alcanzar varios centenares de metros de longitud. Como resultado de las perforaciones manuales de algunas de las anomalías y de la correlación con 


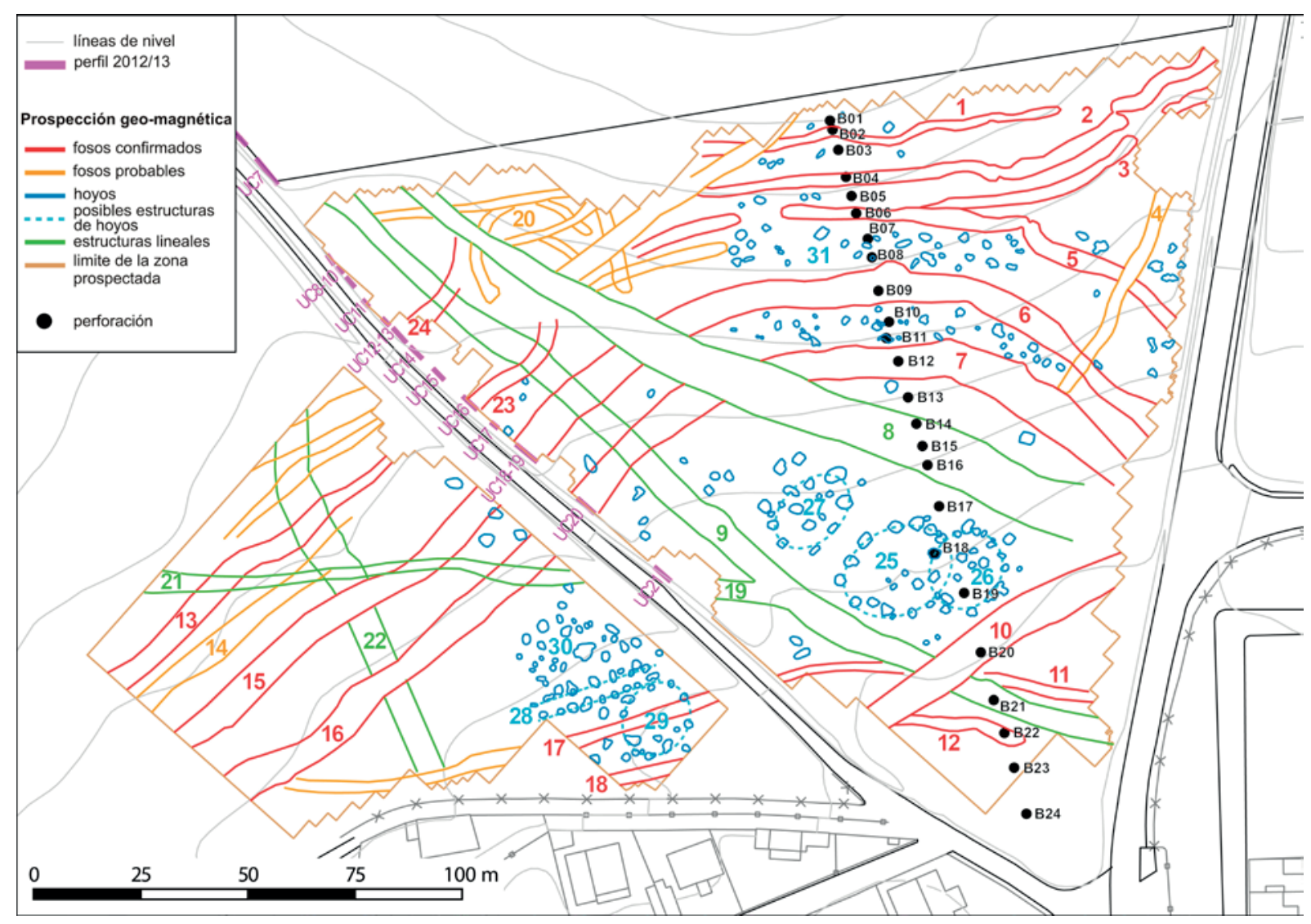

Figura 9. Interpretación y clasificación de las estructuras arqueológicas 1 al 31 según el magnetograma de las parcelas "Parcela municipal del Cerro de la Cabeza" (derecha) y "Cerro Mármol” (izquierda), situación de las perforaciones manuales B1-B24 (transecto) y de las unidades arqueológicas (UC7-UC21) en el perfil del "Camino de Valdegrillo". Lehrstuhl für Vor- und Frühgeschichtliche Archäologie, JMU Würzburg. Mapa base: (C) Instituto Geográfico Nacional de España.

el perfil del Camino de Valdegrillo, podemos definir algunas anomalías de manera segura como estructuras arqueológicas. La interpretación de las anomalías magnéticas sugiere que son segmentos de fosos que podrían corresponder a recintos prehistóricos (fig. 9,1-7. 10-13. 15-18. 23-24); estructuras lineales (fig. 9,8-9. 19. 2122), las cuales podrían ser antiguos caminos históricos; y una gran cantidad de fosas u hoyos que en ocasiones aparecen alineadas de forma rectilínea o circular.

En el límite septentrional de la parcela aparecen tres fosos paralelos documentados a lo largo de unos $200 \mathrm{~m}$ que siguen una dirección oeste-este, con un eje curvo, no lineal, siguiendo las curvas de nivel (figs. 8; 9,1-3). En la parte media aparecen con mucha claridad, mientras que al este y oeste se difuminan. No obstante, en el este podemos seguirlos hasta el borde del área prospectada, aunque el foso 1 parece interrumpirse poco antes de llegar al límite de la parcela. Las anomalías muestran una anchura entre 2.50 y $4 \mathrm{~m}$ y la distancia entre ellos varía entre 4 y $8 \mathrm{~m}$. Perforamos los tres fosos mediante perforaciones manuales (perforaciones B02, B04 y B06) (figs. 9-10). En el caso del foso 1 y la perforación B02, alcanzamos el subsuelo natural a una profundidad a 1'10 m por debajo de la actual superficie. En cambio, en la perforación B01, que se encuentra al lado del foso 1, el subsuelo aparece ya a una profundidad de 0'80 m, lo que hablaría a favor de la interpretación de la estructura 1 como un foso poco profundo. Tuvimos que suspender las perforaciones de los fosos 2 y 3 (B04 y B06) a una profundidad de 2'10 m por cuestiones técnicas, sin haber alcanzado el subsuelo natural. También en este caso el subsuelo natural apareció en las perforaciones efectuadas entre estas anomalías (B03, B05 y B07), ya a una profundidad de 0'70-0'80 m. Por lo tanto, en el caso de las estructuras 2 y 3 se trata sin duda de dos fosos que se adaptan a la topografía del terreno, y transcurren de manera más o menos paralela y tienen una profundidad de más de $2 \mathrm{~m}$ por debajo de la superficie 


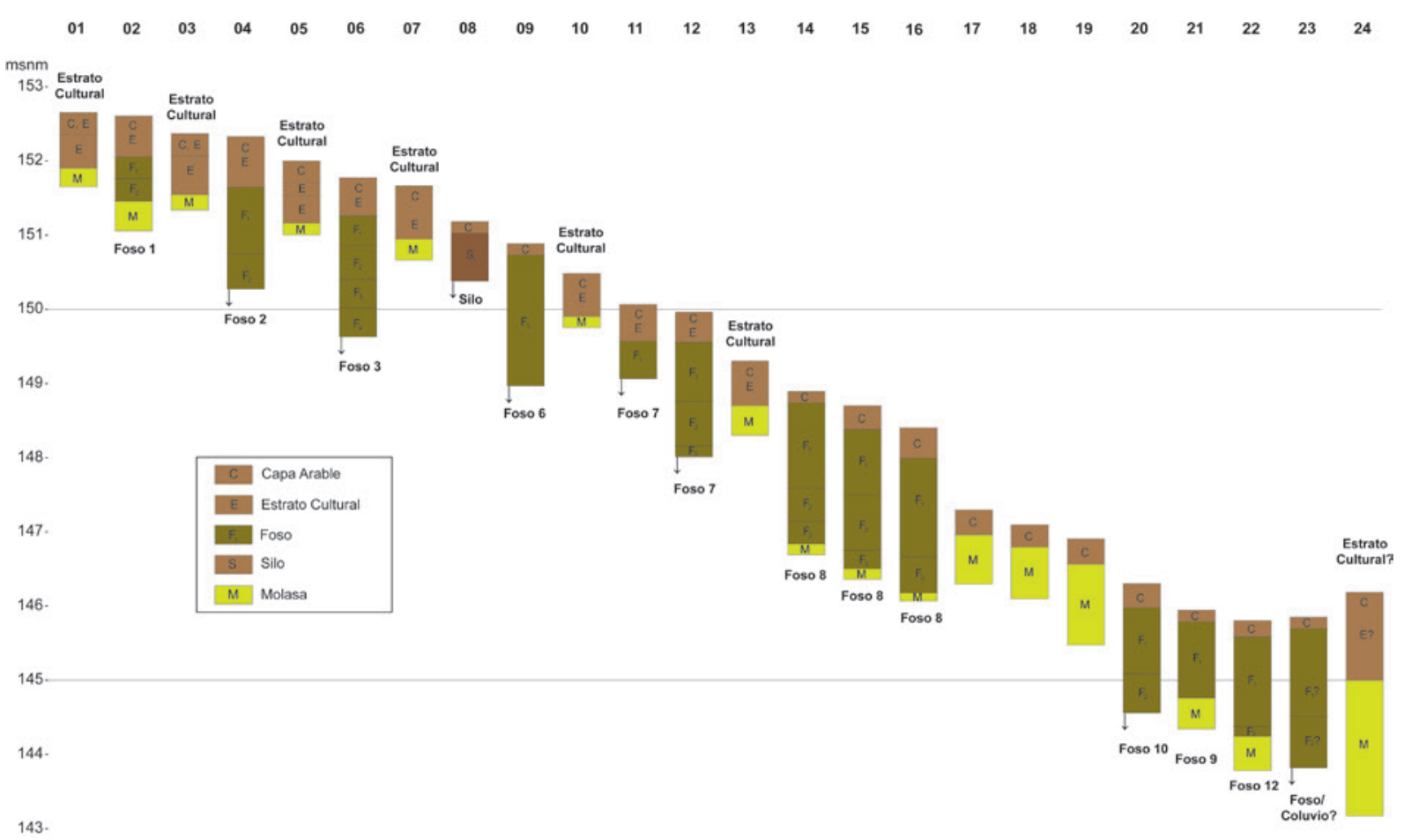

Figura 10. Perfiles litológicos de las perforaciones (transecto norte-sur) en la "Parcela municipal del Cerro de la Cabeza". La numeración corresponde con la de la figura 9. Lehrstuhl für Vor- und Frühgeschichtliche Archäologie, JMU Würzburg.

actual. Por su posición y características como fosos, con una anchura de 3 a $4 \mathrm{~m}$, y una profundidad de 2 a $3 \mathrm{~m}$, parece probable que correspondan con los dos fosos que aparecieron en el año 1976, en la excavación del Museo Arqueológico de Sevilla, un poco más al noreste del Cerro de la Cabeza, y que se pudieron documentar entonces con una longitud de más de 100 m (Fernández Gómez y Ruiz Mata 1978; Fernández Gómez y Oliva 1980 y 1986; Fernández Gómez 2013) (fig. 3).

Más o menos paralela al límite este de la parcela, y a la actual carretera de Valencina a Santiponce, transcurre otra anomalía lineal (estructura 4), que parece sobreponerse al foso 5. Este último transcurre en un arco abierto hacia el sur en dirección noroeste, hasta encontrarse con el foso 3. Parece que el foso 5 converge con el foso 3, convirtiéndose en un único foso que transcurre linealmente, aprovechando su trazado, e incorporándolo dentro de la estructura que forma, o bien se superponen ambos y el foso 5 transcurre a menor profundidad. Pero, en definitiva, la relación entre los fosos 3 y 5 no puede ser aclarada por el magnetograma, sino que esto sólo podría confirmarse con seguridad mediante una excavación arqueológica.

El foso 5 transcurre en paralelo a los fosos 6 y 7, y los tres juntos describen un arco de círculo concéntrico abierto hacia el sur, y que se encuentra entre la actual carretera de Valencina a Santiponce y el Camino de Valdegrillo al oeste. El foso 5 tiene una anchura que oscila entre 3 o $4 \mathrm{~m}$, muestra una interrupción de $9 \mathrm{~m}$ de largo en la parte media de la parcela, lo que podría indicar la presencia de una puerta. El foso intermedio 6, con una mayor anchura de 4 a $6 \mathrm{~m}$, se ve superado por el foso interior 7 con una anchura de $9 \mathrm{~m}$. La distancia entre los fosos 5 y 6 oscila de 12 a $15 \mathrm{~m}$, y entre los fosos 6 y 7 de 7 a $9 \mathrm{~m}$. Mientras los fosos 5-7 son bien visibles en su trazado, se difuminan en la parte occidental de la parcela del Cerro de la Cabeza y en su continuación del Cerro Mármol, donde la señal en el magnetómetro es más débil. Eso no necesariamente refleja una menor profundidad de estas estructuras, sino que, al contrario, podría indicar una mayor sedimentación coluvial que reduce su señal por encontrarse a mayor profundidad, lo que de hecho puede observarse en el perfil del Camino de Valdegrillo. Pero, en parte, las señales magnéticas más débiles se deben también a la dirección de los fosos, que transcurren con orientación suroeste-noreste, y por lo tanto coinciden en paralelo con la dirección principal que seguíamos al efectuar la prospección geomagnética, pues la señal es menos clara si la dirección fuese en sentido opuesto, cortando transversalmente los fosos. 
Se efectuaron perforaciones en la estructura 6 (B09) y estructura 7 (B12); en los dos casos se suspendieron las perforaciones a 1'90-2'00 $\mathrm{m}$ sin haber alcanzado el sustrato natural, el cual aparece en la perforación B10 situada entre las dos estructuras a una profundidad de 0’60 m. Por lo tanto, en estos dos casos se trata de dos fosos paralelos con una anchura sensiblemente mayor que en el caso de la estructura 3, y una profundidad de más de $2 \mathrm{~m}$. Por su trayectoria y la posición de los dos fosos queda claro que las estructuras 6 y 7 coinciden con las estructuras UC18 y UC20 del perfil documentado en el Camino de Valdegrillo (Vargas 2013b) (fig. 5. 9). Además parece que la estructura UC16 de este perfil es la continuación de la anomalía magnética o estructura 5, cuya prolongación, más difuminada, la numeramos de forma diferente como estructura 23, pero que debe ser su continuación. Según la documentación del perfil, como en el caso de las estructuras UC16, UC18, UC19 y UC20, se trata de fosos con perfil en $\mathrm{V}$ y paredes curvas excavados en el subsuelo.

En el perfil del Camino de Valdegrillo se interpretó una cuarta estructura (UC13) como posible foso. Es posible que a esta estructura le corresponda una corta línea oscura en el magnetograma al noroeste de las estructuras 5-7, o estructura 24 , pero en esta posición se encuentra un poste de la luz que desgraciadamente dificulta la prospección geomagnética al crear una interferencia.

Los fosos 6 y 7 deberían tener continuidad al oeste del Camino de Valdegrillo, en la parcela del Cerro Mármol, en forma de dos fuertes anomalías positivas (fosos 15 y 16), que lo lógico es que sean la continuación de estos fosos 6 y 7 .

Más al noroeste se encuentran otras dos anomalías positivas paralelas a las estructuras 15 y 16 , y con dimensiones parecidas (estructuras 13 y 14). Es probable que uno de los dos sea la continuación del foso 5 y 23.

Hay otra anomalía bien visible en la parcela municipal del Cerro de la Cabeza, en forma de línea doble, que transcurre desde la carretera de Valencina a Santiponce en dirección Noroeste (estructura 8). Poco antes de alcanzar el límite septentrional de la parcela estas dos líneas parecen juntarse en una sola. También en este caso se efectuaron varias perforaciones (B14, B15 y B16). En las tres perforaciones se documentó un relleno que finaliza a una profundidad de 2'10-2'20 $\mathrm{m}$ y al que sigue el subsuelo natural. En las dos perforaciones, B13 y B17, situadas al norte y al sur de esta estructura 8 , en cambio se alcanzó el substrato natural a 0’30-0’60 $\mathrm{m}$. Eso significa que en el caso de la estructura 8 , a pesar que parecen tratarse de dos líneas, es posible que realmente se trate de un solo foso (o camino), con una profundidad de 2'20 m por debajo de la superficie actual. Tan solo con la prospección geomagnética no es posible esclarecer la relación entre la estructura 8 y los fosos 5-7, pero la imagen del magnetograma da a entender que la estructura 8 corta los tres fosos 5-7 y sería entonces más reciente.

En el caso de la estructura rectilínea 9, se trata de una anomalía positiva con una anchura de hasta $8 \mathrm{~m}$, que transcurre más o menos paralela al actual camino de Valdegrillo, con excepción de su final meridional que se desvía un poco hacia el Este. La estructura 10, todavía más ancha que la estructura 9 , parece sobreponerse a la estructura 9 . La estructura 9 continúa al sur de la estructura 10 y fue perforada con la localización B21. Aquí se alcanzó el sustrato natural a una profundidad de 1'20 m, lo que podría indicar un foso poco profundo, o incluso un antiguo camino. Una impresión similar nos la dan las estructuras rectilíneas 21 y 22, localizadas en la parcela de Cerro Mármol. En el caso de la estructura 21, parece tratarse de la continuación occidental de la estructura 19. En el caso de la última, que transcurre entre la estructura 9 y el Camino de Valdegrillo, se trata de la estructura UC21, documentada en el perfil del camino (Vargas 2013b) (figs. 5 y 9). Esta estructura tiene un perfil en forma de trapecio, con base plana y más ancha en la parte superior, con una anchura superior de 3'90 $\mathrm{m}$ e inferior de 3’20 m. El magnetograma no ayuda a interpretar esta estructura.

El foso 10 transcurre en el límite meridional de la superficie prospectada, en dirección Suroeste-Noreste. Tiene una anchura entre 8-9 m y según la perforación B20, una profundidad de más de 1'60 $\mathrm{m}$ de la actual superficie. Por sus características y dirección es muy probable que corresponda al foso documentado durante una intervención arqueológica en el año 1995, al este de la carretera Valencina-Santiponce (Cruz-Auñón y Arteaga 1999). Este foso transcurrió en la Estacada Larga en dirección Norte, con una anchura de $7 \mathrm{~m}$ y una profundidad de $4 \mathrm{~m}$.

Al Sur del foso 10 se ve otra anomalía positiva corta (foso 11), que transcurre desde la carretera ValencinaSantiponce en dirección noroeste. Esta estructura la cortan las estructuras 9 y 10 , y finalmente continúa al oeste de estas dos hasta el Camino de Valdegrillo. A una distancia de $8 \mathrm{~m}$ al sur del foso 11, y de forma paralela a éste, transcurre otra anomalía positiva (foso 12). También se ve cortado por el foso 10. En una perforación efectuada en el centro del foso 12 (B22), se alcanzó el sustrato natural a una profundidad de 1'50 m. 
Los fosos 11 y 12 encuentran su continuación al occidente del Camino de Valdegrillo en los fosos 17 y 18. Por lo tanto, parece tratarse de dos líneas paralelas de un recinto, que dibuja un segmento de un círculo.

En el límite noroccidental del Cerro de la Cabeza observamos un grupo de estructuras curvas u ovales que son difíciles de interpretar, y cuya relación entre ellas y con los fosos 1 a 3 y 5 no está clara (estructura 20).

Aparte de los fosos mencionados y otras anomalías rectilíneas, encontramos en amplias zonas de la superficie prospectada docenas de anomalías más pequeñas y de forma oval o circular, que muchas veces presentan señales positivas más intensas que las estructuras lineales. En la mayoría de los casos se debería tratar de estructuras prehistóricas como silos, fondos de cabaña o fosas. Sus dimensiones están entre 1'50 y $5 \mathrm{~m}$. Llama la atención la distribución desigual de estas estructuras. Se concentran, sobre todo, entre los fosos 16 y 18 (agrupación de fosas 28-30), entre las estructuras 8-10 (agrupación de fosas 25-27) y entre los fosos 1 y 7 (agrupación de fosas 31). En cambio, en otras zonas como por ejemplo el área al Sur del foso 7 o la parte occidental de la parcela del Cerro Mármol, no se advierten estructuras, lo que no deja de ser llamativo. Por lo tanto tenemos que contar con la posibilidad de la existencia de un terraplén con la tierra extraída del foso, que también se ha documentado en otros recintos contemporáneos como Perdigões (Reguengos de Monsaraz, Alentejo, Portugal) (Márquez et al. 2011: 183, fig. 5).

La agrupación de fosas 31 muestra una acumulación densa, pero no estructurada, de fosas entre los fosos 1-6. Se observan, de forma más o menos clara, superposiciones de las anomalías lineales por algunas de estas anomalías circulares u ovales en forma de fosa, lo que indicaría que se excavaron las fosas después del relleno de los fosos. Perforamos una de estas posibles fosas (B08) (figs. 9-10), suspendiendo la perforación en un sedimento de relleno a $1 \mathrm{~m}$, sin aún haber alcanzado el sustrato natural. El hecho de que en la perforación B07, situada al norte de la perforación B08, el sustrato natural ya aparece a una profundidad de 0’70 m, sugiere que esa anomalía sería una fosa de más de $1 \mathrm{~m}$ de profundidad. Llama la atención una alineación oval de algunas de esas anomalías en forma de fosa entre las estructuras 8 y 9, y que mide $20 \times 15 \mathrm{~m}$ (agrupación de fosas 25). Inmediatamente al este de esta anomalía se sitúa otra concentración circular de fosas (agrupación de fosas 26), pero esta, en cambio, muestra también algunas fosas mayores en su interior, y con 17 x 15 m es algo más pequeña. Otra de estas alineaciones de anomalías, también con fosas en el interior, se podría encontrar al noroeste de la primera (agrupación de fosas 27).

A modo de posible comparación para estas agrupaciones de fosas podríamos citar algunos fondos de cabañas excavados en el subsuelo y documentados en Camino de Yeseras (San Fernando de Henares, Madrid) y La Deseada (Rivas-Vaciamadrid, Madrid) (Blasco et al. 2007: 153; Liesau et al. 2008: 103, fig. 4; Díaz del Río 2001: 165-173, fig. 23). Estos forman cabañas con planta oval, delimitadas por una serie de agujeros de poste, pero también por fosas de gran tamaño. En su interior se encuentra un agujero de poste central y a veces también algunas fosas. Esas cabañas en Camino de Yeseras tienen una superficie de $140 \mathrm{~m}^{2}$, y datan del Calcolítico Precampaniforme, mientras que en La Deseada corresponden al Neolítico.

En la geomagnética del entorno del monumento funerario de La Pastora se han encontrado algunas agrupaciones circulares de pequeñas anomalías parecidas (Vargas et al. 2012: fig. 6). Sus dimensiones van de 60 $\mathrm{m}$ a $10 \mathrm{~m}$. Se encuentran al lado de otras anomalías circulares de las mismas dimensiones, pero formadas por líneas circulares continúas. Pero en el primer caso no sabemos si se trata del reflejo de estructuras negativas o positivas, ya que no se han efectuado ni perforaciones ni excavaciones. Por la cercanía de varios monumentos y construcciones funerarias, la interpretación de estas estructuras va más en la dirección de pertenecer también al ámbito funerario. Por supuesto, hasta que no se confirme por excavaciones, esta interpretación u otra también parece posible para nuestras agrupaciones de fosas. Pero hay que resaltar, de momento, la escasez de estructuras funerarias en el sector Cerro de la Cabeza y Cerro Mármol, mientras que los hallazgos hechos en superficie, con abundante cerámica común, útiles de sílex, fragmentos de molinos, de tufita y de malaquita hablan más bien a favor de una zona doméstica-productiva. Por eso preferimos una interpretación de las agrupaciones de fosas aparecidas en la campaña de 2014 en este sentido.

Igualmente llama la atención la alineación rectilínea de posibles fosas en el Sur de la parcela Cerro Mármol, donde transcurren dos líneas paralelas de entre 9 y 10 estructuras, a lo largo de una distancia de unos $30 \mathrm{~m}$ (agrupación de fosas 28). Al sur de este observamos otra concentración circular de fosas que mide $9 \mathrm{x}$ $13 \mathrm{~m}$. Al norte de la agrupación 28 se observa otro clúster de fosas, la agrupación $\mathrm{n}^{\mathrm{o}} 30$, sin estructuras claras, sobre una superficie de $20 \times 30 \mathrm{~m}$. 


\section{LAS PERFORACIONES MANUALES}

Después de terminar la prospección geomagnética y la recogida de material de superficie, se efectuaron en la parcela municipal del Cerro de la Cabeza una serie de perforaciones manuales con el sistema EDELMANN. Con ellas esperábamos obtener datos sobre los estratos arqueológicos, composición sedimentaria y profundidad de las estructuras en forma de fosos y fosas identificadas en el magnetograma como anomalías. Aunque las perforaciones únicamente dan una visión puntual, es sustancial para una lectura vertical de la secuencia del relleno de las estructuras. La alineación de perforaciones en transectos también permite la reconstrucción de un perfil del sustrato geológico del terreno.

La interpretación de las perforaciones suministra nuevos datos acerca del asentamiento, pero son preliminares hasta su verificación por excavaciones arqueológicas.

La parcela prospectada se encuentra en la ladera media y baja del Cerro de la Cabeza. El transecto, con una longitud de $160 \mathrm{~m}$, transcurre de manera radial a la cota más elevada, a lo largo de la ladera decreciente del Cerro de la Cabeza, con una diferencia de altitud entre los extremos de 6’50 m (fig. 9). Las 24 perforaciones se situaron con una distancia entre ellas de 1 a $10 \mathrm{~m}$, de manera que algunas estuviesen situadas en anomalías magnéticas y otras en zonas intermedias, sin anomalías, que podrían indicar un sustrato del terreno más elevado. El sistema de perforación de tipo EDELMANN se puede utilizar en suelos que no tienen muchas piedras en el sedimento, con un esfuerzo razonable y de manera accesible hasta una profundidad máxima de 5 a $6 \mathrm{~m}$. El diámetro de la corona de la perforación permite también sacar material arqueológico de pequeñas dimensiones, y se puede documentar su profundidad con un margen de error de $5 \mathrm{~cm}$. Intentamos perforar hasta el subsuelo natural, pero en el caso de las fosas nos paramos en una profundidad de $1 \mathrm{~m}$ para no dañar en demasía a la estructura arqueológica. En el caso de los fosos, paramos la perforación a una profundidad de $2 \mathrm{~m}$, sin haber alcanzado en algunos casos la base del foso. El subsuelo natural lo forman sedimentos de limos arenosos poco compactos del terciario, con un color amarillo-blanquecino, que se diferencia claramente del sedimento arqueológico (fig. 10). La parte superior de los perfiles de perforación lo forman siempre el horizonte superficial afectado por el arado de los cultivos con un grosor de 0’30-0’40 m.
En los primeros $70 \mathrm{~m}$ desde el norte hacia el sur se encontró un sedimento arqueológico con un grosor de 0'80 m (B01, B03 y B05) que ladera abajo se reduce a un grosor de 0'60 m (B07, B10 y B13) y termina en la estructura 8. Este sedimento de color marrón castaño con humus, contiene cerámica y se sobrepone con un fuerte contraste cromático con el suelo natural. Muestra un fuerte porcentaje arcilloso, lo que hace sospechar que en la formación de este sedimento también tuvieron un papel importante los procesos coluviales. Sobre los límites superiores de los rellenos de las fosas y los fosos (fosos 1, 2, 5 y 7), en las perforaciones B02, B04, B06, B08, B11 y B12, se superpone por un lado la parte superior del estrato arqueológico y por otro lado, profundizan en la parte inferior del estrato arqueológico, de eso concluimos que la construcción de los fosos se sitúa cronológicamente dentro de este estrato arqueológico, al haber excavado el foso en un segundo momento durante el proceso de formación del estrato. Probablemente se aportó material al estrato arqueológico resultante de la excavación de los fosos, pero por otro lado los fosos también tuvieron un proceso de relleno propio. Este sedimento arqueológico encuentra su correspondencia en el estrato inferior del sedimento arqueológico del Camino de Valdegrillo. Posiblemente este estrato con sedimento arqueológico esté presente, con grosor y composición variable, en toda la ladera septentrional y occidental de la "Parcela municipal del Cerro de la Cabeza".

Inmediatamente al sur de la estructura 8 , ya no se puede documentar estratos arqueológicos fértiles (B17, B18 y B19). Aquí, el estrato superior arado se encuentra por encima del subsuelo natural. En esta parte se encuentra un escalón difuminado en el terreno pero que se puede intuir, que hace suponer que en esta parte, después del relleno de la estructura 8 , se ha procedido a retirar sedimentos de forma artificial por acción antrópica, más que por procesos erosivos muy intensos.

Con las perforaciones B08 y B11 se estudiaron dos de las fosas identificadas en el magnetograma (agrupación de fosas 31). Estas fosas se encuentran entre los fosos 5-7, en la parte donde se documentó sedimento arqueológico. Mientras a la fosa más meridional B11 se le superpone el sedimento arqueológico, el relleno de la fosa (B08), situada más al norte y en una cota superior, llega hasta el estrato superficial arable.

De los recintos prehistóricos propuestos que se identifican en el magnetograma pudimos estudiar siete fosos mediante una perforación (fig. 9). De estos obtenemos datos sobre la profundidad mínima de los fosos, su relleno y su relación estratigráfica con el sedimento arqueológico (fig. 10). 
Probablemente se perforó el foso 1 tan solo en su borde (B02), por lo que tiene sólo una profundidad de 1'10 m de la superficie actual. Al relleno del foso se le superpone el sedimento arqueológico con un grosor de 0’50 m. Teniendo en cuenta que el sedimento arqueológico al norte y al sur del foso tiene un grosor de 0’80 m, se puede suponer que se excavó el foso desde la parte inferior del sedimento arqueológico, en un segundo momento una vez ya iniciado el proceso de formación del estrato.

Una posición estratigráfica parecida, dentro del estrato arqueológico, muestran los fosos 2, 5 y 6 . Se pudo seguir al foso 2 que transcurre en paralelo al foso 1 , hasta una profundidad de $2 \mathrm{~m}$ (B04). Al relleno amarillento del foso, con un grosor de 1'40 m, se le superpone el estrato arqueológico con un grosor de 0'60 m. Probablemente la parte inferior del relleno del foso, con una composición más arcillosa, refleja procesos de relleno coluvial sobre la base del foso, cuando éste estaba aún abierto (B04, F2).

Todavía más complicado se presenta el relleno del foso 5, que tiene una profundidad mínima de 1'60 $\mathrm{m}$ (B06). Aquí se pueden distinguir tres rellenos de color marrón claro (B06, F1-F3), que están separados del sustrato natural por un sedimento coluvial por encima del fondo del foso (B06, F4). En cambio, el foso 6, con una profundidad de 1'90 m, muestra un relleno apenas estructurado, que en la parte superior está más suelto y en la inferior más compacto y arcilloso. Probablemente este foso se llenó lentamente por la erosión natural desde sus bordes. Parece significativo que el límite superior del relleno llega hasta el sedimento superficial arable, por lo que en comparación con la formación del estrato arqueológico debe ser estratigráficamente más reciente. Por lo tanto, los resultados de las perforaciones verifican la observación hecha en el perfil del Camino de Valdegrillo que se encuentra a $100 \mathrm{~m}$ más hacia el Oeste, donde el foso 6 encuentra su correspondencia en el foso UC18-UC19, que muestra dos fases y es estratigráficamente más reciente.

En el foso 7, que transcurre en paralelo al foso 6, se documentaron tres estratos de relleno con un grosor mínimo total de 1'60 m (B12, F1-F3), al que se superpone un sedimento arqueológico bien visible. También en este caso, el perfil verifica y complementa las observaciones hechas por las perforaciones. El foso 7 encuentra su correspondencia en el foso UC20, que muestra un perfil en $\mathrm{V}$ y cuya excavación debe corresponder justo al momento inicial del estrato calcolítico, precisamente el foso más interior y más ancho.
En resumen, podemos deducir de la posición estratigráfica de los límites superiores de los fosos, en su relación con el grosor del estrato arqueológico sobre ellos superpuesto, algunos indicios acerca de la relación cronológica relativa de los distintos recintos. Por lo tanto, el recinto septentrional, formado por los fosos 1 y 2 , debería indicar una construcción más antigua, mientras que el foso 5 y su convergencia con el foso 3 se sitúa cronológicamente entre este recinto más antiguo y el recinto más reciente que se encuentra más al sur, o fosos 6 y 7. Dentro de este recinto más reciente parece que el foso interior 7 es más antiguo que el foso más exterior 6 .

Otros fosos probablemente prehistóricos que se encuentran al pie de la ladera, y tienen una profundidad de 1'50 m (foso 12), o como mínimo 1'60 m (foso 10), también muestran un estrato coluvial por encima del fondo y por debajo del sedimento de relleno (B20, F2; B22, F2).

Aparte de los recintos de fosos probablemente prehistóricos, también se han investigado mediante perforaciones otras estructuras rectilíneas. En estos casos probablemente se trate de antiguos caminos históricos (fig. 9). Las tres perforaciones efectuadas en la estructura 8 (B14-B16), nos revelan un foso con una profundidad de 2'30 m, que presenta en su parte inferior rellenos coluviales y en la parte superior otro tipo de relleno (fig. 10).

Hay que resaltar que la cota del límite superior del relleno del foso está 1'10 m por encima del nivel de la superficie actual justamente al sur del foso 8 , como si existiera un escalón artificial, resultado de trabajos de aterrazamiento, que actualmente está más difuminado por la acción del arado y la uniformización de las tierras en superficie. Este hecho ha sido confirmado por la información oral recibida.

\section{LA PROSPECCIÓN SUPERFICIAL CON RECOGIDA DE MATERIAL ARQUEOLÓGICO}

En la parcela municipal del Cerro de la Cabeza se efectuó una prospección superficial con recogida de material arqueológico aprovechando la retícula que teníamos trazada para la prospección geomagnética. La intención era obtener datos acerca de las estructuras documentadas por la prospección geomagnética, sus dimensiones, funcionalidad y cronología mediante la elaboración de mapas de distribución cuantitativos y cualitativos de los artefactos recuperados. Sobre la base del sistema de retículas de 30 x 30 m utilizado para la prospección geomagnética, dividimos la superficie en 
una retícula de cuatro cuadrantes de 15 x 15 m., mediante cintas métricas. Ya que la retícula rectangular no se ajusta a la superficie triangular de la parcela en sus límites, en los bordes de la retícula sólo corresponden a una parte de la misma. Esto se tuvo en cuenta en el tratamiento de los datos, calculando no el número total de hallazgos, sino la densidad de hallazgos, $\mathrm{n}^{\circ}$ o peso por superficie prospectada.

La superficie estaba libre de vegetación y se había arado, e incluso apenas estaba erosionada. Estaba disponible para la prospección, pero la visibilidad de los artefactos era limitada por haber numerosos terrones de tierra compactados del arado, no haber llovido hacía tiempo y la elevada luminosidad en el momento que se realizó la prospección. Aun así, creemos que se recogió material de superficie en una cantidad representativa. Se prospectaron 110 cuadrantes, siendo recorridos en varias pasadas por dos o tres prospectores, hasta recoger todo el material visible, principalmente cerámica, pero también artefactos líticos, tanto tallados como pulimentados. Se inventariaron todos los artefactos de cerámica y de material lítico separados por cuadrantes. De los cantos de río alóctonos y de tufita sólo se recogió una cantidad representativa. El material de superficie recuperado fue limpiado, secado, procesado y empaquetado en las dependencias de la Casa de la Cultura de Valencina de la Concepción, después se procedió a cuantificarlo, pesarlo y clasificarlo por grupos de material. Distinguimos cerámica a mano, cerámica a torno, artefactos líticos genéricos y artefactos de sílex específicos. Entre la cerámica a mano también determinamos el número de fragmentos cronológicamente definibles. Los artefactos líticos se diferenciaron en molinos, alisadores, percutores y abrasivos. Aparte registramos la presencia de material lítico alóctono como tufita, cantos de río y malaquita. Excepcionalmente se recuperaron algunos otros artefactos como útiles metálicos o fragmentos de vasos de piedra. Se hicieron fotos del material estudiado y se dibujó una selección de los artefactos.

Se encontró cerámica prehistórica a mano en prácticamente todas las unidades de recogida, aunque en densidades variables (3.212 fragmentos, 44'5 kg). Como base para la elaboración de los mapas de densidad utilizamos el peso que parece más representativo que el número de fragmentos recogidos (fig. 11).

Los fragmentos cerámicos identificables pertenecen, con la excepción de algunos fragmentos de la Edad del Hierro, al Calcolítico Medio Precampaniforme por la ausencia de las cazuelas carenadas del Calcolítico Inicial (vide infra). La distribución de los fragmentos calcolíticos corresponde prácticamente a la distribución del total de la cerámica a mano. De esto podemos deducir que la distribución de la cerámica prehistórica refleja sobre todo la situación durante el Calcolítico Medio.

Mientras en la ladera meridional y occidental observamos una densidad menor de fragmentos cerámicos, encontramos una intensa distribución de cerámica en una superficie de $150 \times 75 \mathrm{~m}$ en la parte superior de la parcela. Dentro de esta distribución podemos distinguir tres concentraciones de hallazgos vecinas, con un diámetro máximo entre 30 y $60 \mathrm{~m}$. La concentración central y la occidental muestran una coincidencia remarcable con la concentración de fosas detectadas por la prospección geomagnética (clúster de fosas 31), situada entre dos de los recintos de fosas (fig. 9,31). El límite meridional y occidental de esta concentración de cerámica coincide prácticamente al 100 \% con el área de este clúster de fosas.

A lo largo del transecto de perforaciones, la concentración superficial de artefactos domésticos coincide con la extensión del sedimento arqueológico documentado y que tiene un grosor entre 0'80-0'60 m. Ya que el arado solamente penetra un máximo de $0^{\prime} 40 \mathrm{~m}$ en el estrato arqueológico, estos hallazgos deben representar las actividades domésticas correspondientes a la parte más reciente del estrato arqueológico.

Los mapas de distribución de los artefactos líticos verifican que la distribución de las cerámicas refleja zonas de actividad domestica calcolítica. Así encontramos en el área de concentración de los fragmentos cerámicos, artefactos líticos como láminas, raspadores y núcleos de sílex en un número superior, al igual que fragmentos de molinos. Percutores de piedras de río están presentes, sobre todo, al exterior de esta superficie doméstica de actividades calcolíticas (fig. 12).

También el mapa de distribución de la tufita es muy parecido al de los percutores sobre cantos de río. Encontramos este material volcánico importado, sobre todo en forma de materia prima o parcialmente desbastado. Llama la atención que falten tanto productos acabados como hachas o azuelas, que deberían estar asociados al desforestado de bosques próximos y al trabajo de la madera, como productos semiacabados de tufita en casi todos los cuadrantes. La distribución parecida de fragmentos de tufita y de percutores en la parte inferior de la ladera sur y occidental, hace suponer que son reflejo de un proceso de producción específico (fig. 12). En esta área también se extiende una débil distribución de cerámica doméstica calcolítica que se sobrepone al pie de la ladera sobre tres agrupaciones de fosas 25-27. La distribución de hallazgos más dispersa debe ser el resultado de los trabajos de extracción de tierra documentado en 


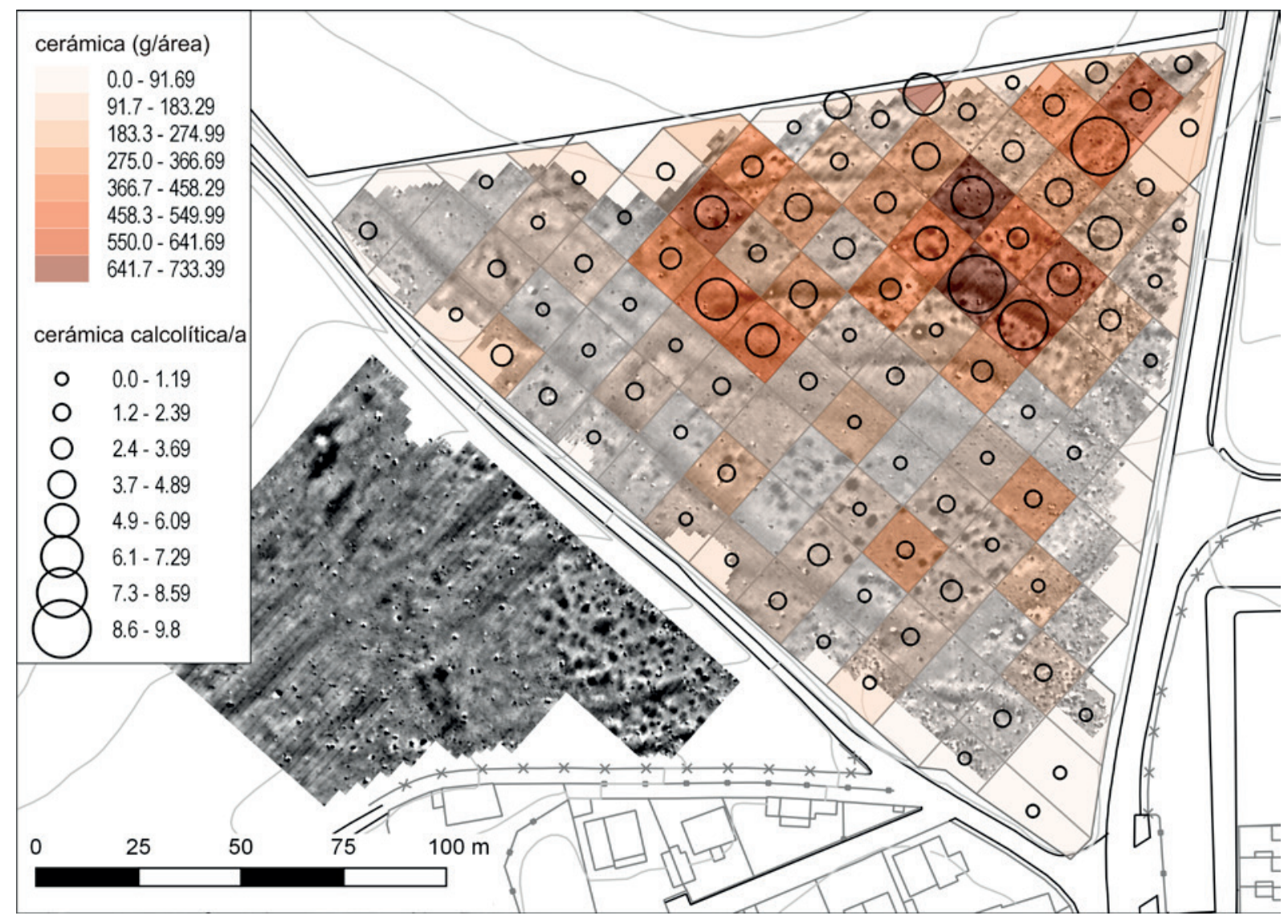

Figura 11. Superficies prospectadas en la "Parcela Municipal del Cerro de la Cabeza" y el "Cerro Mármol": Magnetograma, recogida sistemática de material en superficie con densidad de la cerámica y distribución cuantitativa de fragmentos cerámicos calcolíticos. Lehrstuhl für Vor- und Frühgeschichtliche Archäologie, JMU Würzburg. Mapa base: (C) Instituto Geográfico Nacional de España.

las perforaciones. Eso provoca que la distribución del material en la superficie no sea suficientemente representativa y no se corresponda con la distribución de las fosas documentadas. La distribución uniforme de la cerámica a torno, que probablemente date de época romana y de forma mayoritaria histórica, la cual aparece en cantidades poco representativas ( 745 fragmentos), hace suponer que estas cerámicas llegaron a través de trabajos agrarios junto con aportes de abono o de basura doméstica.

\section{ARTEFACTOS RECUPERADOS DURANTE LA PROSPECCIÓN ARQUEOLÓGICA}

Durante la prospección sistemática en la "Parcela municipal del Cerro de la Cabeza" se recogieron 3.212 fragmentos cerámicos a mano, con un peso total de $44^{\prime} 5 \mathrm{~kg}$ y 750 fragmentos de cerámica a torno, con un peso de 10 '2 kg. De estos fragmentos, 435 pertenecen a vasijas calcolíticas de diferentes tipologías. Aparte de dos fragmentos de borde del Hierro Inicial (Pellicer et al. 1983: 165, fig. 67, 668) (fig. 14,17), uno de una lámpara fenicia (Niemeyer y Schubart 1976: lám. 6,279) (fig. 14,16) y varios romanos, entre ellos algunos fragmentos de terra sigillata. No se encontraron cerámicas de otras épocas. Además, pudimos identificar 56 artefactos de sílex (fig. 15), y se documentaron 11 fragmentos de molinos de diversos materiales, entre ellos granitos, dos recipientes de piedra y fragmentos de malaquita (fig. 15,13).

La mayor parte de los bordes calcolíticos pertenecen a platos, como suele ser habitual en los poblados calcolíticos del Suroeste (Ruiz Mata 1975b). Estos ya se identificaron entre el material de las primeras excavaciones en el área habitacional de Valencina. Entre 


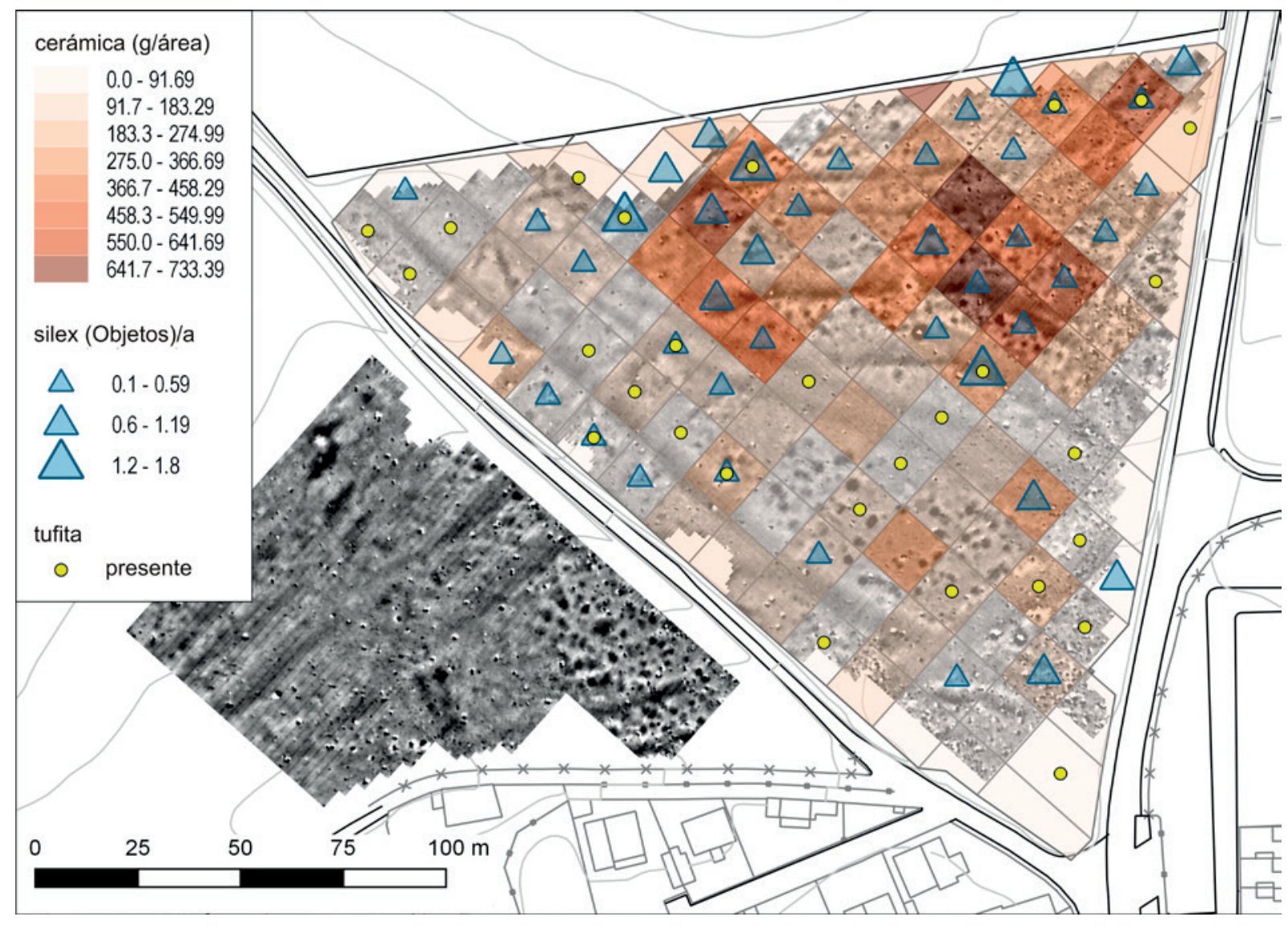

Figura 12. Superficies prospectadas en la "Parcela Municipal del Cerro de la Cabeza" y el "Cerro Mármol": Magnetograma, recogida sistemática de material en superficie con densidad de la cerámica y distribución cuantitativa de objetos de sílex (triángulos azules) y de fragmentos de tufita (puntos amarillos). Lehrstuhl für Vor- und Frühgeschichtliche Archäologie, JMU Würzburg. Mapa base: (C) Instituto Geográfico Nacional de España.

otros encontramos platos de borde almendrado, entre los que podemos distinguir ejemplares más planos y otros más profundos (Ruiz Mata 1975a: 96 fig. 3,1; Ruiz Mata 1975b: 130 fig. 3,2; Fernández Gómez y Oliva 1985: 84 fig. 73,39; Tavares da Silva y Soares 1985: 9 fig. 6,7) (fig. 14,13). Por lo menos en un caso, un plato con borde almendrado muestra dos acanaladuras debajo del borde (Ruiz Mata 1975a: 97 fig. 4,3 y 5,1; Ruiz Mata 1975b: 134 fig. 5,4, Fernández Gómez y Murillo Díaz 2009: fig. 24) (fig. 14, 4). En este caso se podría tratar de una forma más reciente dentro del Calcolítico, porque Ruiz Mata resaltó que estos aparecían en el corte excavado por él en 1971 en los estratos más recientes (Ruiz Mata 1975a: 84). Generalmente, se considera a los platos con borde almendrado como forma cronológicamente diagnóstica, que sustituyen progresivamente a las cazuelas carenadas del Calcolítico Inicial. Estos platos que presentan borde almendrado aparecen por primera vez en la fase Papa Uvas IV (Martín de la Cruz y Miranda 1988: 61 gráfico 13). Por esta razón, Martín de la Cruz y Miranda relacionan el material precampaniforme de Valencina con esta fase de Papa Uvas IV. Solamente en el llamado "horno" del corte C de 1975 faltan estos platos y en cambio hay presencia mayoritaria de las cazuelas carenadas, lo que sugiere que esta estructura sería coetánea a la fase Papa Uvas III. En los Castillejos de Montefrío (Granada), encontramos platos con borde almendrado en las fases III y IV de las excavaciones antiguas, y en la fase VI de las nuevas campañas (Arribas y Molina 1980: 21, 25 fig. 10F; Cámara et al. 2005: 843). En Monte da Tumba (Torrão, Alentejo), aparecen sobre todo en la fase I, y su porcentaje disminuye en la fase II (Tavares da Silva y Soares 1985: 15).

Otras formas de platos son los de borde levantado, de los que aparecen dos variantes, una con el borde 


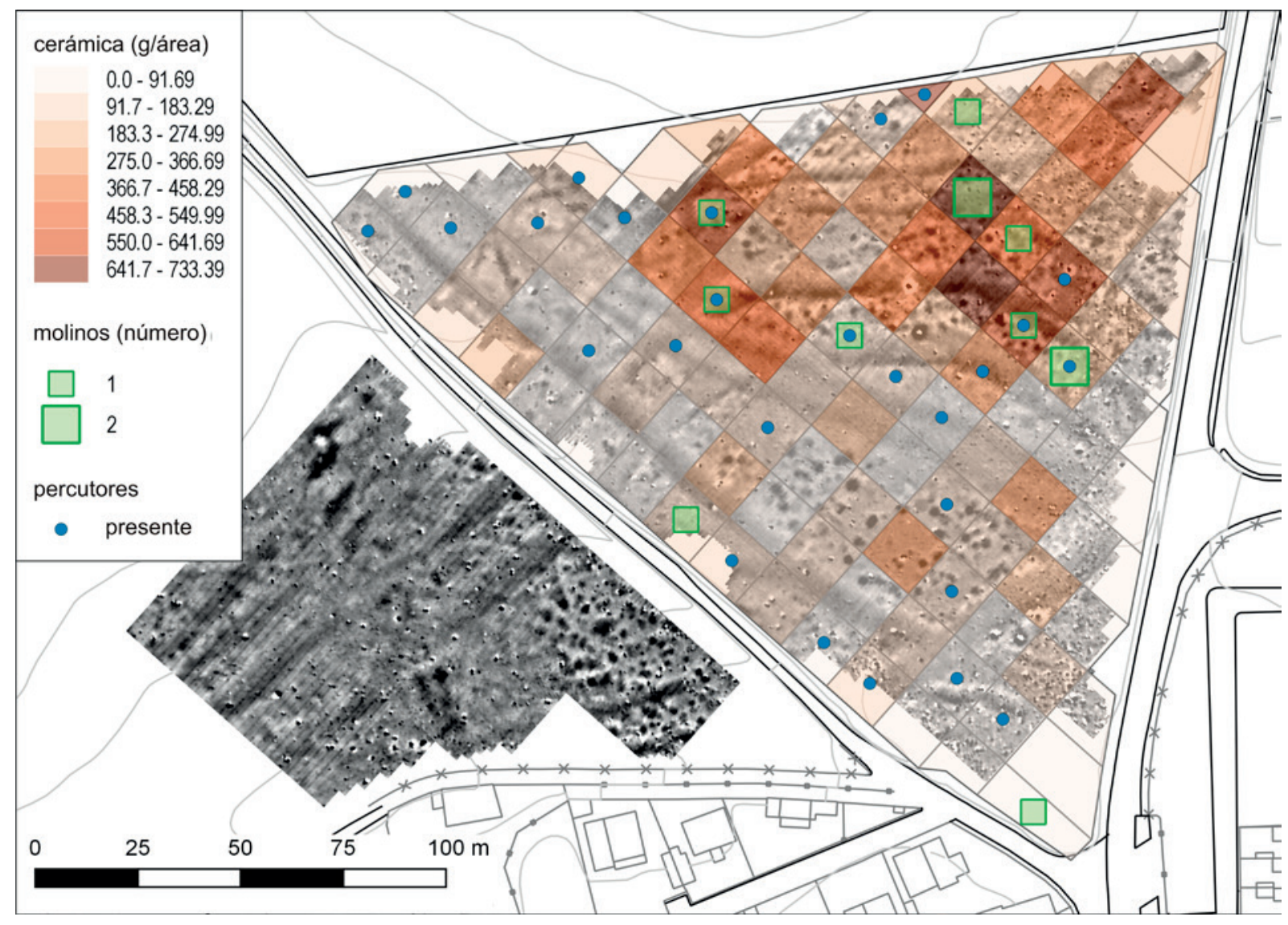

Figura 13. Superficies prospectadas en la "Parcela Municipal del Cerro de la Cabeza" y el "Cerro Mármol": Magnetograma, recogida sistemática de material en superficie con densidad de la cerámica y distribución cuantitativa de fragmentos de molinos y de percutores. Lehrstuhl für Vor- und Frühgeschichtliche Archäologie, JMU Würzburg. Mapa base: (C) Instituto Geográfico Nacional de España.

vertical (Ruiz Mata 1975b: 137 fig. 7,3.13; 8,8; 8,10; Fernández Gómez y Oliva 1985: 86 fig. 75,169; Tavares da Silva y Soares, 1985: 12, fig. 8,1; Fernández Gómez y Murillo Díaz, 2009: 81 fig. 28) (fig. 14,2) y otra con el borde convergente hacia el interior (Ruiz Mata 1975: 99 fig. 6,8.21; Fernández Gómez y Oliva 1985: fig. 75,1-2; Tavares da Silva y Soares 1985: 6 fig. 4,17) (fig. 14,1). Los platos de borde levantado están en Valencina entre los tipos cerámicos menos frecuentes, aparecen en las estructuras del corte $\mathrm{C}$ excavado en 1975, más frecuentemente en el foso en V que en el foso en U (Fernández Gómez y Oliva 1985: 86). Ambas estructuras pertenecen al Calcolítico Medio, pero es posible que el foso en U comience antes (Martín de la Cruz y Miranda 1988: 65, gráfico 12-13).

Otros platos pertenecen a la variante de borde biselado (Ruiz Mata 1975b: 144 fig. 2, 10/1; Fernández Gómez y Oliva 1985: 87 fig. 77/170-171) (fig. 14,7.9).
Estos estaban representados en el corte C de 1975 de forma irregular. Así son poco frecuentes en el foso en $\mathrm{U}$, faltan en el foso en $\mathrm{V}$ y son más abundantes en el denominado "silo" (Fernández Gómez y Oliva 1985: 86; Martín de la Cruz y Miranda 1988: 66). Ya que Martín de la Cruz y Miranda consideran el silo como la estructura más reciente del corte $\mathrm{C}$, podríamos deducir que se trate, dentro del Calcolítico Precampaniforme, como una forma ligeramente más reciente.

Con frecuencia aparecen también simples cuencos o fuentes semiesféricas (Ruiz Mata 1975a: 104 fig. 11,3; Fernández Gómez y Oliva 1985: 100 fig. 94,190) (fig. $14,10)$, mientras que la olla con paredes rectas y borde engrosado al exterior e interior es poco frecuente (Fernández Gómez y Oliva 1985: 97, fig. 90,186) (fig. 14,11). Además pudimos distinguir una posible olla piriforme, con borde vertical (Ruiz Mata 1975a: 105 fig. 12,2; Fernández Gómez y Oliva 1985: 94-98) (fig. 14,12). Es 


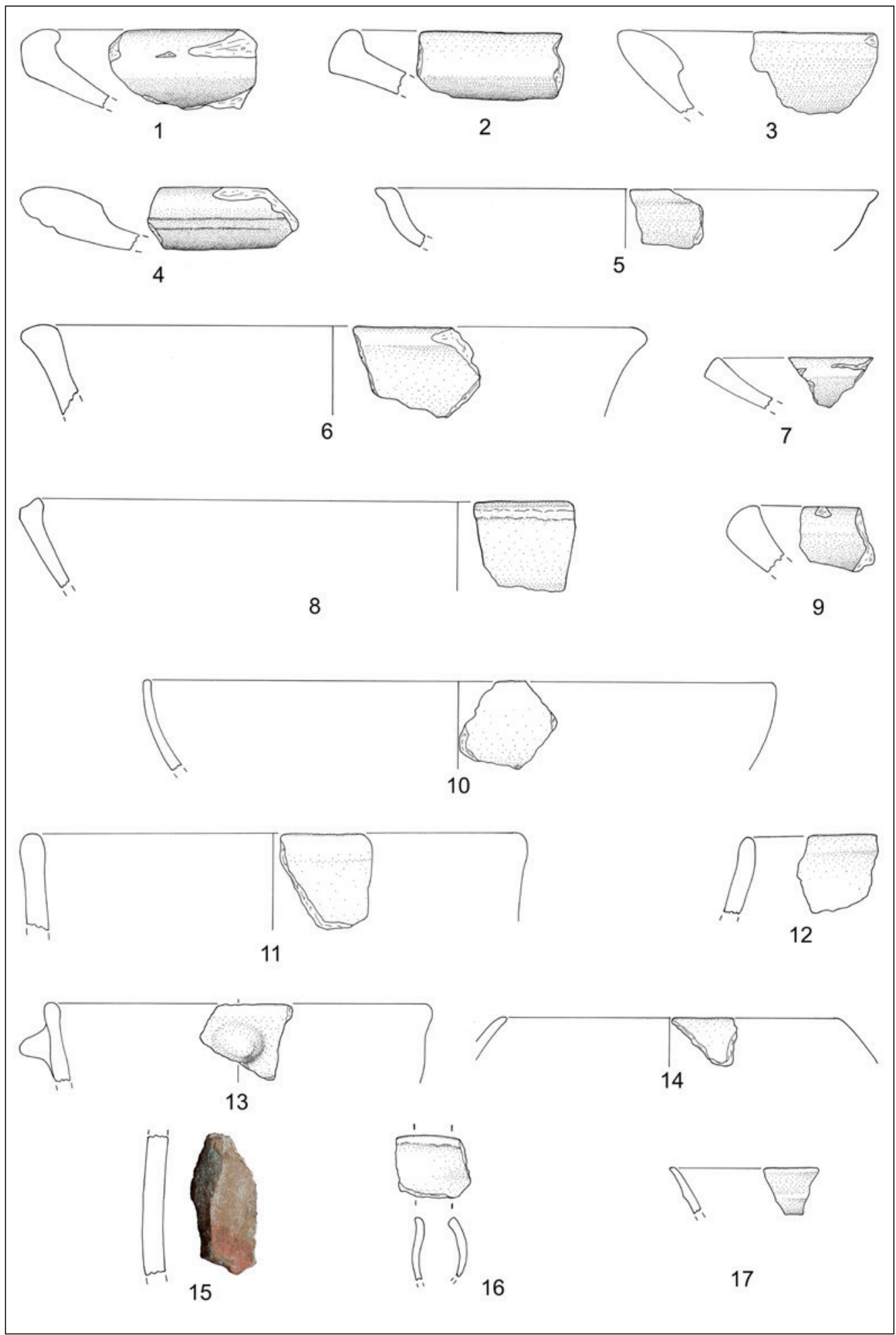

Figura 14. Valencina de la Concepción, "Parcela municipal del Cerro de la Cabeza". Hallazgos encontrados durante la recogida sistemática de material en superficie. 1-15 Fragmentos cerámicos del Calcolítico; 15 Fragmento pintado; 16 Fragmentos de una lámpara fenicia; 17 Fragmento cerámico de la Edad del Hierro. Escala 1:3. Lehrstuhl für Vor- und Frühgeschichtliche Archäologie, JMU Würzburg. 
muy rara entre las excavaciones previas en Valencina la fuente semiesférica con borde recto ligeramente divergente y engrosamiento exterior del labio (Ruiz Mata 1975a: 101 fig. 8,1; Fernández Gómez y Oliva 1985: 93 fig. 85,262) (fig. 14,5). Piezas parecidas aparecen en la fase I de Monte da Tumba (Tavares da Silva y Soares 1985: 6 fig. 4,11). Fernández Gómez y Oliva solamente pudieron identificar pocos ejemplares de la fuente con paredes divergentes y borde engrosado al exterior (Fernández Gómez y Oliva 1985: 96 fig. 90,185) (fig. 14,6), mientras que no podemos nombrar ningún paralelo para la fuente honda con paredes divergentes y labio más levantado hacia el interior, como si al exterior pudiese ponerse una tapadera (Ruiz Mata 1975a: 105 fig. 12,19) (fig. 14,8). En cambio, ollas globulares son frecuentes en el así llamado horno (Ruiz Mata 1975a: fig. 10,10 y 12,6; Fernández Gómez y Oliva 1985: 95-97 fig. 87,137; 88,201; Martín de la Cruz y Miranda 1988: 61 gráfico 13; Tavares da Silva y Soares 1985: 7 fig. 5,10) (fig. $14,14)$, por lo tanto deberían pertenecer, al igual que la olla con perfil ligeramente en $\mathrm{S}$ y mamelón debajo del borde (fig. 14,13), al material más antiguo recuperado en la prospección. En Monte da Tumba, ollas globulares aparecen también en fase I.

Además encontramos varios fragmentos con decoración pintada con franjas rojas o negras sobre el fondo más claro (fig. 14,15). Cerámicas de este tipo conocemos de varios yacimientos calcolíticos del suroeste y sureste de la península ibérica, pero siempre son piezas excepcionales (Molina Grande 1990; Carrasco y Pachón 2010: fig. 1,6). En Valencina de la Concepción, sobre todo los dos fosos y varias fosas y pozos documentados en 1976 suministraron una docena de estos fragmentos pintados (Murillo Díaz y Fernández Gómez 2008; Fernández Gómez y Murillo Díaz 2009). Los contextos respectivos pertenecen sobre todo al Calcolítico Medio, lo que refuerza una datación de carbono 14 del pozo 31 del Cerro de la Cabeza, que está en relación con estos fragmentos $(\mathrm{I}-10.187: 4050 \pm 105$ B.P. $=2858-2470$ cal BC) $($ todas las dataciones de carbono-14 de este artículo han sido calibradas con OxCal v4.2, desarrollado por Bronk Ramsey, con una desviación estándar de 1 Sigma). Pero en las nuevas excavaciones de los Castillejos de Montefrío aparecen cerámicas con motivos pintados en rojo o negro, ya en la fase IV, que según la única datación de carbono 14 de esta fase data a finales del cuarto milenio a.C., Beta-135.665: $4480 \pm 40$ B.P. $=3332-3095$ cal BC (Cámara et al. 2005: 842 tabla 2).

En resumen, podemos deducir que en la parcela prospectada por nosotros no se encuentran hallazgos que podamos datar en época campaniforme, en cambio el material encuentra buenos paralelos en el Calcolítico Medio Precampaniforme, sobre todo en la fase I de Monte da Tumba, Papa Uvas IV y Castillejos de Montefrío fase III (fase VI de las nuevas campañas), pero todavía las estratigrafías bien documentadas o contextos con dataciones absolutas en el suroeste de la península ibérica son poco frecuentes. Además, todavía no se ha publicado mucho material cerámico de estos contextos. En consecuencia, las secuencias cronológicas todavía necesitan refinarse. Aun así, podemos deducir que la mayor parte de nuestro material pertenece a un Calcolítico Medio, y en concordancia con las dataciones absolutas que disponemos de Monte da Tumba I, Papa Uvas IV y Castillejos de Montefrío III, podríamos datar nuestro material en su mayoría entre $c a$. 2800-2500 a.C. (Castro et al. 1996: ${ }^{\circ}$ 1241, 1355-1363, 1469, 1471; Mederos 1996: 55, 57, 73; Molina et al. 2004: tabla 2). Sin embargo, algunos fragmentos deberían ser más antiguos y sugieren que la ocupación de este sector del yacimiento debió comenzar antes. Eso también corresponde con las dataciones de carbono-14 que tenemos para Valencina de la Concepción, y que datan mayoritariamente entre 2900 y 2600 a.C. (García Sanjuán 2013: 26-30 fig. 7).

\section{CONCLUSIONES}

Valorando que se trata de unos resultados preliminares derivados de una prospección geomagnética y arqueológica y que por lo tanto necesitan de su confirmación mediante excavaciones, podemos avanzar unas primeras conclusiones proponiendo a modo de hipótesis de trabajo la existencia de tres posibles recintos.

\subsection{Recinto 1}

Mediante prospección geomagnética y perforaciones manuales detectamos en el borde septentrional de la parcela del Cerro de la Cabeza lo que podría formar el recinto 1 , con tres fosos paralelos, que siguen las curvas de nivel sobre una longitud de $150 \mathrm{~m}$ (fosos 1-3, fig. 8-10). Mientras que el foso interior 1 era menos ancho y profundo, los fosos exteriores 2 y 3 tenían originalmente más de 1'40 $\mathrm{m}$ de profundidad. Interrupciones en el borde oriental de la parcela hacen suponer la existencia de posibles accesos dentro de estos tres fosos. Estos dos o tres fosos paralelos, según el sector, ya fueron detectados en las excavaciones de 1976, en su prolongación hacia el noreste. 


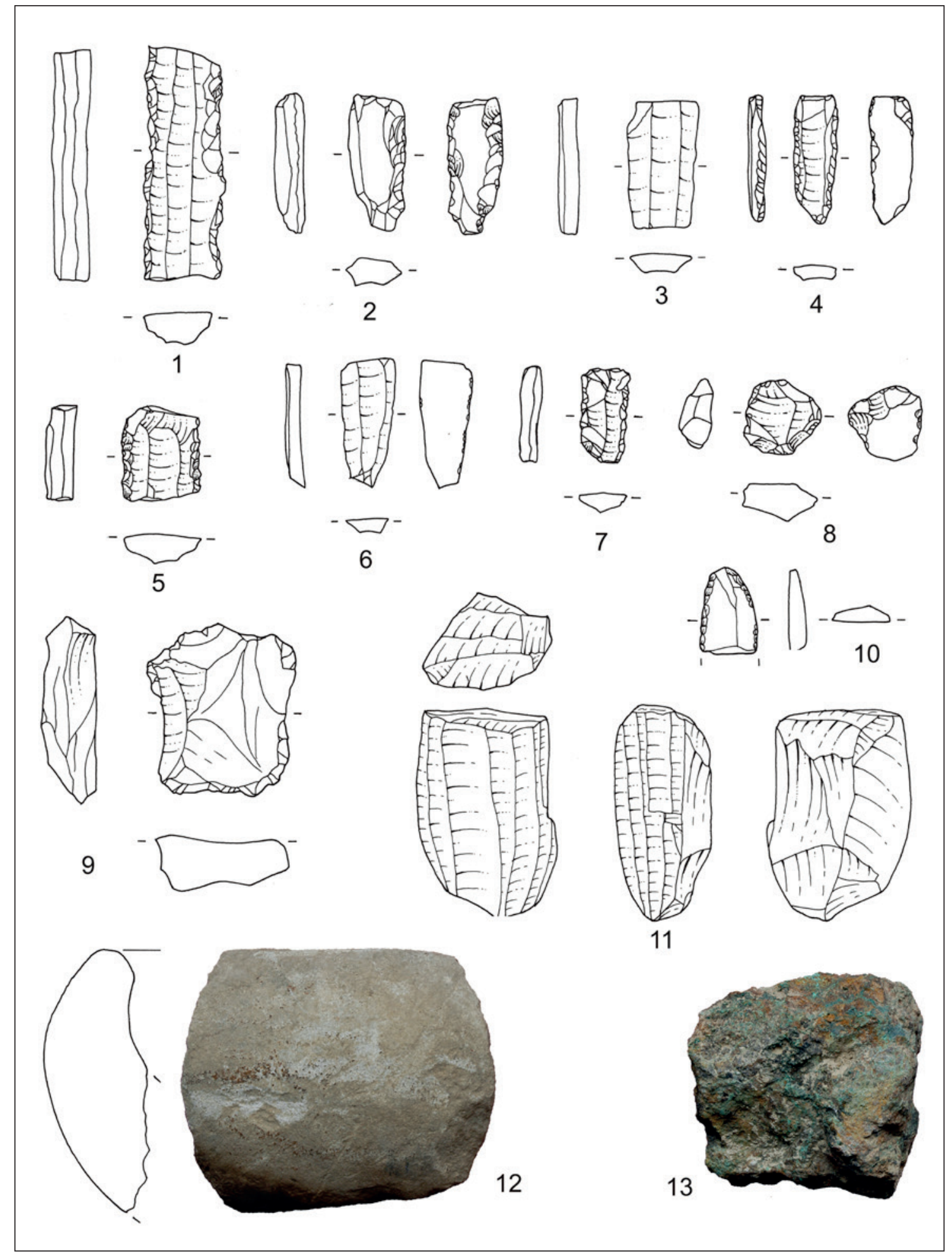

Figura 15. Valencina de la Concepción, "Parcela Municipal del Cerro de la Cabeza". Hallazgos encontrados durante la recogida sistemática de material en superficie. 1-7, 10 Láminas de sílex; 8-9 Útiles de sílex (raspadores); 11 Núcleo de sílex; 12 Fragmento de un recipiente de piedra caliza (?); 13 Mineral de cobre, malaquita. 1-12: Escala 1:2; 13: Escala 1:4. Lehrstuhl für Vor- und Frühgeschichtliche Archäologie, JMU Würzburg. 
Esto nos lleva a la conclusión de que los fosos 1-3 quizás formen parte de un recinto 1 , que cierra el acceso por el sur a los dos espolones que conforman el Cerro de la Cabeza (Fernández Gómez y Oliva 1986; Fernández Gómez 2013). En este caso, el recinto 1 en forma de arco podría cerrar un área de 10 ha del resto del poblado al sur (figs. 3 y 9), aunque este hecho habría que confirmarlo en el futuro, tal vez para separar un área funeraria como proponen Cruz-Auñón y Mejías (2013) por la presencia de un tholos descubierto en 1975 en el Cerro de la Cabeza. En realidad, hoy en día es imposible reconstruir el emplazamiento original de este enterramiento (Fernández Gómez y Ruiz Mata 1978; Fernández Gómez y Oliva 1980; Fernández Gómez 2013), pero parece que el tholos se encontró más al sur de los fosos descubiertos un año después. Por eso parece más probable que el recinto 1 separase durante algún tiempo un sector diferenciado del poblado en el Cerro de la Cabeza. No queda claro si algunas de las fosas detectadas en el magnetograma entre los fosos 1-3 y al norte de éstos son contemporáneas. Fernández Gómez y Oliva (1986) también mencionan en su excavación en 1976 fosas a ambos lados de los fosos.

Parece que cuando se excavaron los fosos del recinto 1 ya existía en la ladera meridional del Cerro de la Cabeza un fino estrato arqueológico acumulado por actividades antrópicas habitacionales. Por otro lado, puesto que a los fosos amortizados del recinto 1 se superpone un estrato arqueológico y el material recogido en superficie, parece que el recinto 1 es más antiguo que el poblado de la ladera, datado en el Calcolítico Medio.

\subsection{Recinto 2}

Claramente visible en el magnetograma son los fosos de un posible segundo recinto en la "Parcela municipal del Cerro de la Cabeza", que tiene su prolongación en la parcela vecina del Cerro Mármol hacia el oeste (figs. 8. 9). Este posible recinto 2, documentado sobre una longitud de $290 \mathrm{~m}$ comprende por lo menos tres fosos paralelos, fosos 5/23/13, $6 / 15$ y $7 / 16$, que hemos dividido porque son cortados por el trazado del Camino de Valdegrillo. Los recintos 1 y 2 están en contacto en el caso de los fosos 3 y 5 , lo que habla en contra de que ambos sean contemporáneos. Probablemente se construyó el recinto 2 cuando el recinto 1 quizás ya estaba abandonado, o al menos en este sector del foso 3 . El recinto 2 describe un cuarto de círculo abierto hacia el sur y se prolonga de manera lineal en dirección suroeste. Parece muy probable que el recinto 2 delimite un área poblacional en llano, en la base de los cerros de la Cabeza y Mármol. Esta área se encuentra en el extremo superior de una barranquera, que podía servir para acceder al poblado.

Según los resultados de las perforaciones manuales y las observaciones en el Camino de Valdegrillo, parece que el foso central 6/15 (UC 18/19 de la prospección de Camino de Valdegrillo) era claramente más reciente que el foso interior, 7/16 (UC 20). Probablemente la formación de la mayor parte del sedimento arqueológico de la ladera sur del Cerro de la Cabeza pertenece al momento de funcionamiento del recinto 2 .

Los tres segmentos de foso del recinto 2 forman fosos en $\mathrm{V}$, con una anchura de 3 a 4'50 $\mathrm{m}$ (fosos 5/23/13 -UC 16- y 6/15 -UC18-19- y 7/16 -UC 20-) (fig. 9). Parece que el foso exterior 5 muestra en su parte más septentrional una entrada con una anchura de unos 10 m. Otras estructuras de tipo foso en el noroeste de la "Parcela municipal del Cerro de la Cabeza" y en el norte de la parcela del Cerro Mármol igualmente podrían pertenecer al recinto 2 . Aquí hay que mencionar, sobre todo, la estructura semicircular 20, con un diámetro de unos $30 \mathrm{~m}$, que parece tener relación con el foso $5 / 23$. Se podría tratar de un foso con forma de bastión o entrada protegida en forma de pinza de cangrejo. Entradas de este tipo encontramos en los recintos calcolíticos de Perdigões (Reguengos de Monsaraz, Portugal), Fuente de la Mora (Leganés, Madrid) y tal vez en la zona de El Cuervo-La Pastora de la propia Valencina (Vargas et al. 2012: 133-134), aparte de que son frecuentes en los recintos chassenses de la Francia atlántica (Márquez et al. 2011: 183 fig. 6; Díaz del Río 2003: fig. 4; Márquez y Jiménez Jaimez 2010: 257 fig. 117). Otros posibles paralelos para el foso semicircular 20 podrían ser pequeños recintos como la estructura 10.024 del sector PP4-Montelirio, o fosos que delimitan túmulos funerarios en el mismo sector de Valencina (Mora et al. 2013: 274 figs. 13. 18. 20). En cambio, una interpretación como fosos de cimentación de cabañas, como los conocemos de Gózquez de Arriba (San Martín de la Vega, Madrid), Fuente de la Mora (Leganés, Madrid) y Camino de Yeseras (San Fernando de Henares, Madrid), parece poco probable por las dimensiones de la estructura 20 (Díaz del Río 2001: 173 fig. 28; idem 2003: 69 figs. 2. 4). Así, los diámetros de las cabañas mencionadas están entre 6 y 7’50 m.

Indicios sobre elementos de este tipo encontrados en otros puntos del poblado de Valencina de la Concepción nos pueden dar una idea aproximada sobre las dimensiones de este posible recinto. Así en una 
excavación de urgencia de pequeña envergadura en la Avenida Andalucía 9, se documentaron tres fosos paralelos que transcurrieron en dirección este-oeste (Sardá 2013). El foso más ancho era el septentrional, de 3'405'50 m. Se excavó el sedimento de relleno de este foso hasta una profundidad de 1'83 m, sin haber alcanzado el subsuelo natural. Según una datación de carbono 14, UBAR-1024/CNA-001: $3780 \pm 60 \mathrm{BP}=2298-2056 \mathrm{cal}$ $\mathrm{BC}$, se podría deducir que el relleno del foso sucedió en la fase final del Campaniforme. Los otros dos fosos, con una anchura entre 1'50-2'40 m eran bastante más estrechos. Por tratarse de tres fosos paralelos como los documentados por nosotros en el sector norte, fosos $5 / 23 / 13,6 / 15$ y $7 / 16$, por su situación topográfica si los ubicamos en la planimetría del yacimiento, y por su dirección, es posible que estos fosos sean parte de la prolongación meridional de nuestro recinto 2 . Por supuesto, la pertenencia de ambos sectores con tres fosos paralelos a un posible segundo recinto resulta hipotética hasta que no se confirme mediante futuras intervenciones.

Además en otra excavación de urgencia de pequeñas dimensiones, en la calle Mariana Pineda, en el límite occidental del municipio de Valencina, se documentó otro foso con una anchura de $2 \mathrm{~m}$, sobre una longitud de $150 \mathrm{~m}$ (Moro et al. 2010; Pajuelo y López Aldana 2013). Este foso transcurre en dirección norte, y llega a la barranquera de Los Pozos que podía servir como punto de acceso al poblado. Los fosos del recinto 2, documentados en la parcela del Cerro Mármol, en su prolongación, deberían llegar a la misma barranquera, prácticamente enfrente del foso encontrado en la calle Mariana Pineda. De excavarse una superficie más amplia podría ser incluso tres fosos, y ser así, serían la prolongación meridional de nuestro posible recinto 2 .

\subsection{Las estructuras al interior del recinto 2}

Las agrupaciones de fosas del 25 al 30 en la base de las laderas del Cerro de la Cabeza y del Cerro Mármol deberían delimitar un área poblacional continua (fig. 9). Si suponemos que cada agrupación de fosas representa una estructura doméstica, el poblado en el área prospectada comprendería entre cinco y seis estructuras domésticas. En el caso de las agrupaciones de fosas 25, 26, 27 y 29 suponemos, como hipótesis de trabajo, que se tratase de posibles áreas de habitación entre 15 y $30 \mathrm{~m}$ de diámetro, rodeadas y delimitadas concéntricamente por fosas, y con cabañas situadas en el centro, aunque la geomagnética no haya detectado directamente los vestigios de la cabaña en sí. Como demuestran las superposiciones de las agrupaciones de fosas 25 y 26, y también entre las agrupaciones de fosas 28, 29 y 30, no todos estos posibles espacios domésticos eran contemporáneos. La alineación doble de la agrupación 28, con una longitud de $30 \mathrm{~m}$, difiere de este principio de alineación concéntrica de fosas. Tal vez documentamos aquí un área funcional especializada dentro del poblado que pudiese servir como espacio estructurado y alineado de almacenamiento o de ritual.

Las áreas poblacionales en la base de la ladera del Cerro de la Cabeza (agrupación de fosas 25-27), no se reflejan en un mayor volumen de hallazgos en la superficie, ya que parece que esta área fue alterada por extracciones de tierras (figs. 11-13). Los pocos hallazgos cerámicos superficiales sugieren una datación en el Calcolítico Medio Precampaniforme por la ausencia de las cazuelas carenadas del Calcolítico Inicial.

El área poblacional de la base de la ladera del Cerro de la Cabeza y del Cerro Mármol se encuentra dentro del recinto 2. Parece que se incluyó premeditadamente dentro del recinto 2 por el trazado de los fosos que rodean en forma de arco a las agrupaciones de fosas. Una franja sin estructuras a lo largo de la parte interior del foso 7 hace suponer la existencia de un terraplén al interior del foso más interno, que también tuviese finalidad defensiva. Parece razonable suponer que el poblado del pie de la ladera y el recinto 2 son contemporáneos, aunque no se puede verificar sin una excavación arqueológica. Ya que los fosos del recinto 2 sobrepasan en el suroeste y sureste el área de superficie prospectada, el área del recinto y del espacio poblacional debió ser de mayores dimensiones.

\subsection{Recinto 3}

En el límite meridional del área prospectada de la "Parcela municipal del Cerro de la Cabeza" y de la parcela del "Cerro Mármol", observamos en el magnetograma un posible tercer recinto (fig. 9). Se trata de dos fosos paralelos que transcurren en arco, fosos $11 / 17$ y $12 / 18$, que tienen poca anchura y según el resultado de la perforación B22, una profundidad de más de 1'50 m. Según el espacio prospectado, parece que el posible recinto 3 es similar al recinto 2 pero con una superficie menor. Al foso exterior 17 se superponen las fosas de la agrupación 29, lo que indica que el recinto 3 es más antiguo que el área poblacional del pie de la ladera del Cerro de la Cabeza y Cerro Mármol. 
Suponiendo que el poblado del pie de la ladera y el recinto 2 son contemporáneos, la construcción del recinto 3 podría ser anterior.

\subsection{Un sector poblacional en la ladera media}

La prospección geomagnética, la recogida de material en superficie y las perforaciones manuales nos permiten proponer un área poblacional en la ladera media del Cerro de la Cabeza igualmente datado en el Calcolítico Medio Precampaniforme (figs. 8-13). Esta área con una superficie de 0’7 ha, está definida por la agrupación de fosas 31 y tres grandes concentraciones de material en superficie. Entre las piezas más representativas encontramos materiales cerámicos, artefactos de sílex y fragmentos de molinos. Tanto algunas de esas fosas como de las concentraciones de hallazgos, y también un estrato arqueológico documentado en las perforaciones, se sobreponen a los fosos de los recintos 1 y 2. Eso indica que este espacio poblacional continuó en uso después del abandono de los recintos 1 y 2 .

\section{RECAPITULACIÓN}

Los resultados de la campaña de prospección de 2014 en la parte septentrional del poblado de Valencina de la Concepción fueron excepcionales. Con prospecciones geomagnéticas, perforaciones manuales y recogida sistemática de material en superficie durante las dos semanas de la campaña, sobre una superficie de 3 ha, pudimos documentar tres recintos prehistóricos con un mínimo de ocho fosos, dos áreas habitacionales con más de 200 fosas y aproximadamente 3.000 artefactos calcolíticos en superficie. El sedimento arqueológico detectado en extensión en la ladera sur del Cerro de la Cabeza apunta hacia la existencia de suelos de uso de época calcolítica precampaniforme que hasta el momento no se han documentado en las excavaciones (García Sanjuán 2013). Los resultados de las prospecciones muestran un poblamiento muy intenso y dinámico, de momento sólo en el Calcolítico Medio, sobre una superficie de pocas hectáreas, donde se suceden varios posibles recintos y diferentes áreas habitacionales. A los recintos 1 y 3 , supuestamente más antiguos, sigue el recinto 2 con su área habitacional contemporánea al pie de la ladera. Los resultados de las perforaciones manuales y las superposiciones de algunas de esas áreas habitacionales sugieren varias fases para el recinto 2. Después del relleno del foso más reciente de este recinto, se establece un área habitacional en la ladera sur del Cerro de la Cabeza sin la delimitación y probable protección de los fosos. La ausencia de cerámica campaniforme sugiere un abandono de esta área habitacional en un momento avanzado del Calcolítico Medio.

Las parcelas en el área septentrional del perímetro urbano del núcleo de Valencina de la Concepción, con su gran cantidad de hallazgos y estructuras arqueológicas, ofrecen un enorme potencial para la investigación arqueológica. Con una combinación de prospecciones en extensión, de carácter sistemático y excavaciones puntuales, apoyado por prospecciones geoarqueológicas y geomagnéticas, sería posible estudiar áreas suficientemente representativas de este gran asentamiento calcolítico.

\section{Agradecimientos}

La financiación fue aportada por la Bayerische Forschungsallianz y el fondo de investigación de la Facultad de Filosofía de la Universidad Julius-Maximilian de Würzburg. La tramitación fue siempre facilitada por la gentil amabilidad del arqueólogo provincial de Sevilla, José Manuel Rodríguez Hidalgo. El Ayuntamiento de Valencina de la Concepción nos aportó todo tipo de ayuda logística y nos permitió la utilización de la infraestructura de la Casa de Cultura-Museo Municipal, gracias al apoyo del alcalde, Antonio Suárez Sánchez, la concejala de Cultura, Sonia Arellano González y de la directora de la Casa de Cultura, Maribel Sagrera. La prospección en el Cerro del Mármol fue posible gracias a la gentil autorización de D. Joaquín González. En el equipo de trabajo de campo también participaron dos estudiantes de la Universidad de Würzburg, Franz Bechtold y Philipp Schinkel. En el procesado del material de superficie nos ayudaron cuatro alumnas del taller municipal de empleo, Beatriz Canto Morales, Inmaculada Fernández Tejada, María Asunción González Díaz y Angélica Morales Arce.

\section{BIBLIOGRAFÍA}

Arribas, A. y Molina González, F. (1980): “Nuevas aportaciones al inicio de la metalurgia en la Península Ibérica. El poblado de Los Castillejos de Montefrío (Granada)", en M. Ryan (ed.), The Origins of Metallurgy in Atlantic Europe. 5th Atlantic Colloquium: 7-34. Dublin (1978), Dublin, The Station Office. 
Arteaga, O. y Roos, A.M". (1995): “Geoarchäologische Forschungen in Umkreis der marismas am Río Guadalquivir (Niederandalusien)". Madrider Mitteilungen 36: 199-218.

Belén Deamos, M. (1991): “Apuntes para una historia de la Arqueología Andaluza: Francisco M. Tubino (1833-1888)". Boletín del Museo Arqueológico Nacional 9: 6-15.

Blasco, C.; Delibes, G.; Baena, J.; Liesau, C. y Ríos, P. (2007): "El poblado calcolítico de Camino de las Yeseras (San Fernando de Henares, Madrid): un escenario favorable para el estudio de la incidencia campaniforme en el interior peninsular". Trabajos de Prehistoria 64 (1): 151-163. doi.org/10.3989/ tp.2007.v64.i1.99

Bronk Ramsey, C. (2009): "Bayesian analysis of radiocarbon dates". Radiocarbon 51 (1): 337-360.

Cámara, J.A.; Molina, F. y Afonso, J.A. (2005): “La cronología absoluta de Los Castillejos en Las Peñas de los Gitanos (Montefrío, Granada)", en P. Arias, R. Ontañón y C. García-Moncó (eds.), III Congreso del Neolítico de la Península Ibérica: 841852. Santander (2003), Santander, Universidad de Santander.

Carrasco, J. y Pachón, J.A. (2010): “Las cerámicas neolíticas pintadas y su relación con los soportes muebles orgánicos de la 'Cueva de los Murciélagos' de Albuñol (Granada)". Archivo de Prehistoria Levantina 28: 107-137.

Castro, P.V.; Lull, V. y Micó, R. (1996): Cronología de la Prehistoria Reciente de la Península Ibérica y Baleares (c. 2800-900 cal ANE). Oxford, British Archaeological Reports. International Series, 652.

Costa Caramé, M.E.; Díaz-Zorita, M.; García Sanjuán, L. y Wheatley, D.W. (2010): "The Copper Age settlement of Valencina de la Concepción (Seville, Spain): demography, metallurgy and spatial organization". Trabajos de Prehistoria 67 (1): 85-118. doi.org/10.3989/tp.2010.10032

Cruz-Auñón, R. y Arteaga, O. (1999): “Acerca de un campo de silos y un foso de cierre prehistóricos ubicados en 'La Estacada Larga' (Valencina de la Concepción, Sevilla). Excavación de urgencia de 1995”. Anuario Arqueológico de Andalucía 1995. III. Actividades de Urgencia: 600-607. Sevilla, Consejería de Cultura de la Junta de Andalucía.

Cruz-Auñón, R. y Mejías, J.C. (2013): “Diversidad de prácticas funerarias e identidades en el yacimiento de Valencina de la Concepción (Sevilla)", en L. García Sanjuán, J.M. Vargas, V. Hurtado, T. Ruiz Moreno y R. Cruz-Auñón (eds.), El asentamiento prehistórico de Valencina de la Concepción (Sevilla): investigación y tutela en el 150 aniversario del descubrimiento de La Pastora: 175-199. Valencina de la Concepción-Sevilla (2010), Sevilla, Universidad de Sevilla.

Díaz del Río Español, P. (2001): La formación del paisaje agrario: Madrid en el III y II milenios BC. Arqueología, Paleontología y Etnografía 9. Madrid, Comunidad de Madrid.

Díaz del Río Español, P. (2003): "Recintos de fosos del III milenio AC en la Meseta peninsular". Trabajos de Prehistoria 60 (2): 61-78. doi.org/10.3989/ tp.2003.v60.i2.81

Fernández Flores, A. y Aycart, V. (2013): “Montelirio. Un sepulcro clave para la comprensión del registro de los grandes monumentos megalíticos de Valencina de la Concepción-Castilleja de Guzmán (Sevilla)", en L. García Sanjuán, J.M. Vargas, V. Hurtado, T. Ruiz Moreno y R. Cruz-Auñón (eds.), El asentamiento prehistórico de Valencina de la Concepción (Sevilla): investigación y tutela en el 150 aniversario del descubrimiento de La Pastora: 233259. Valencina de la Concepción-Sevilla (2010), Sevilla, Universidad de Sevilla.

Fernández Gómez, F. (2013): “Las excavaciones del Museo Arqueológico de Sevilla en Valencina de la Concepción (Sevilla) en 1975-1976: sectores de La Perrera, La Candelera y Cerro de la Cabeza”, en L. García Sanjuán, J.M. Vargas, V. Hurtado, T. Ruiz Moreno y R. Cruz-Auñón (eds.), El asentamiento prehistórico de Valencina de la Concepción (Sevilla): investigación y tutela en el 150 aniversario del descubrimiento de La Pastora: 131-150. Valencina de la Concepción-Sevilla (2010), Sevilla, Universidad de Sevilla.

Fernández Gómez, F. y Murillo Díaz, T. (2009): “Las cerámicas pintadas de la Edad del Cobre en Valencina de la Concepción (Sevilla), con sus contextos". Temas de Estética y Arte 23: 43-82.

Fernández Gómez, F. y Oliva, D. (1980): “Los ídolos calcolíticos del Cerro de la Cabeza (Valencina de la Concepción, Sevilla)". Madrider Mitteilungen 21: 20-44.

Fernández Gómez, F. y Oliva, D. (1985): “Excavaciones en el yacimiento Calcolítico de Valencina de la Concepción (Sevilla). El corte C ('La Perrera')". Noticiario Arqueológico Hispánico 25: 7-131.

Fernández Gómez, F. y Oliva, D. (1986): "Valencina de la Concepción (Sevilla). Excavaciones de urgencia”. Revista de Arqueología 58: 19-33.

Fernández Gómez, F. y Ruiz Mata, D. (1978): “El tholos del Cerro de la Cabeza, en Valencina de la 
Concepción (Sevilla)". Trabajos de Prehistoria 35: 193-224.

García Sanjuán, L. (2013): “El asentamiento de la Edad del Cobre de Valencina de la Concepción: estado actual de la investigación, debates y perspectivas", en L. García Sanjuán, J.M. Vargas, V. Hurtado, T. Ruiz Moreno y R. Cruz-Auñón (eds.), El asentamiento prehistórico de Valencina de la Concepción (Sevilla): investigación y tutela en el 150 aniversario del descubrimiento de La Pastora: 21-59. Valencina de la Concepción-Sevilla (2010), Sevilla, Universidad de Sevilla.

García Sanjuán, L. y Murillo Barroso, M. (2013): “Social complexity in Copper Age Southern Iberia (c. 3200-2200 cal BC): reviewing the 'state' hypothesis at Valencina de la Concepción (Seville, Spain)”, en M. Cruz Berrocal, L. García Sanjuán y A. Gilman (eds.), The Prehistory of Iberia: Debating Early Social Stratification and the State: 119-140. Vancouver, Canada (2008), New York, Routledge.

García Sanjuán, L.; Luciañez, M.; Schuhmacher, T.X.; Wheatley, D. y Banerjee, A. (2013): "Ivory Craftsmanship, Trade and Social Significance in the Southern Iberian Copper Age: The Evidence from the PP4-Montelirio Sector of Valencina de la Concepción (Seville, Spain)". European Journal of Archaeology 16 (4): 610-635. doi.org/10.1179/14619 57113Y.0000000037

Liesau, C.; Blasco, C.; Ríos, P.; Vega, J.; Menduiña, R.; Blanco, J.F.; Baena, J.; Herrera, T.; Petri, A. y Gómez, J.L. (2008): "Un espacio compartido por vivos y muertos: El poblado calcolítico de fosos de Camino de Yeseras (San Fernando de Henares, Madrid)". Complutum 19: 97-120.

Márquez, J.E. y Jiménez Jáimez, V. (2010): Recintos de fosos: genealogía y significado de una tradición en la Prehistoria del suroeste de la Península Ibérica (IVIII milenios a.C.). Málaga, Universidad de Málaga.

Márquez, J.E.; Varela, A.; Becker, H.; Jiménez Jáimez, V. y Suárez, J. (2011): “El Complexo Arqueológico dos Perdigões (Reguengos de Monsaraz, Portugal). Prospecciones Geofísicas - Campaña 200809”. Trabajos de Prehistoria 68 (1): 175-186. doi. org/10.3989/tp.2011.11065

Martín de la Cruz, J.C. y Miranda, J.M. (1988): “El poblado Calcolítico de Valencina de la Concepción (Sevilla): una revisión crítica". Cuadernos de Prehistoria y Arqueología de la Universidad Autónoma de Madrid 15: 37-67.

Martín Espinosa, A. y Ruiz Moreno, Ma.T. (1992): "Excavación calcolítica de urgencia en la finca 'La
Gallega'. $1^{\text {a }}$ fase. Valencina de la Concepción, Sevilla". Anuario Arqueológico de Andalucía 1990. III. Actividades de Urgencia: 455-458. Sevilla, Consejería de Cultura de la Junta de Andalucía.

Mederos Martín, A. (1996): “La cronología absoluta de Andalucía occidental durante la prehistoria reciente (6100-850 A.C.)". Spal 5: 45-86. doi.org/10.12795/ spal.1996.i5.03

Mederos Martín, A. (2000): "Puntas de jabalina de Valencina de la Concepción (Sevilla, España) y del área palestino-israelita". Madrider Mitteilungen 41: 83-111.

Molina González, F.; Cámara, J.A. y Capel, J. (2004): "Los Millares y la periodización de la Prehistoria reciente del Sureste", en Simposios de Prehistoria Cueva de Nerja. II. La problemática del Neolítico en Andalucía. III. Las primeras sociedades metalúrgicas en Andalucia: 142-158. Nerja (1998 y 2000), Nerja (Málaga), Fundación Cueva de Nerja. Molina Grande, Ma .C. (1990): "La Cueva de los Tiestos (Jumilla, Murcia). La cerámica pintada", en Homenaje a Jerónimo Molina: 51-72. Murcia, Real Academia Alfonso X el Sabio.

Mora Molina, C.; García Sanjuán, L.; Peinado, J. y Wheatley, D.W. (2013): "Las estructuras de la Edad del Cobre del sector PP4-Montelirio del sitio arqueológico de Valencina de la Concepción-Castilleja de Guzmán (Sevilla)", en L. García Sanjuán, J.M. Vargas, V. Hurtado, T. Ruiz Moreno y R. CruzAuñón (eds.), El asentamiento prehistórico de Valencina de la Concepción (Sevilla): investigación y tutela en el 150 aniversario del descubrimiento de La Pastora: 261-279. Valencina de la ConcepciónSevilla (2010), Sevilla, Universidad de Sevilla.

Moro, F.J.; López Aldana, P. y Lobo, A. (2010): "Nuevos datos para el conocimiento de la ocupación humana durante el Calcolítico Pleno y Final en el cuadrante noroccidental de Valencina de la Concepción”, en J.A. Pérez Macías y E. Romero (eds.), IV Encuentro de Arqueología del Sureste Peninsular: 372-393. Aracena (2008), Huelva, Universidad de Huelva. CD-rom.

Murillo Díaz, Ma .T. y Fernández Gómez, F. (2008): "Las cerámicas pintadas de la Edad del Cobre en Valencina de la Concepción (Sevilla)". Espacio, Tiempo y Forma. Prehistoria y Arqueología, Serie I 1: 299-314.

Murillo Díaz, Ma.T.; Fernández Gómez, F. y Oliva, D. (2006): "Una cabaña de la Edad del Cobre en Valencina de la Concepción (Sevilla)". Revista de Humanidades 14 (2004-05): 177-196. 
Niemeyer, H.G. y Schubart, H. (1976): Trayamar. Die phönizischen Kammergräber und die Niederlassung an der Algarrobo-Mündung. Madrider Beiträge 4. Mainz.

Nocete, F.; Queipo de Llano, G.; Sáez, R.; Nieto, J.M.; Inácio, N.; Rodríguez Bayona, M.; Peramo, A.; Vargas, J.M.; Cruz-Auñón, R.; Gil-Ibarguchi, J.I. y Santos, J.F. (2008): "The smelting quarter of Valencina de la Concepción (Seville, Spain): the specialised copper industry in a political centre of the Guadalquivir valley during the Third Millennium BC (2750-2500 BC)". Journal of Archaeological Science 35: 717-732. doi.org/10.1016/j. jas.2007.05.019

Ortega Gordillo, M. (2013): "El registro estratigráfico en el Pabellón Cubierto de Valencina de la Concepción (Sevilla)", en L. García Sanjuán, J.M. Vargas, V. Hurtado, T. Ruiz Moreno y R. Cruz-Auñón (eds.), El asentamiento prehistórico de Valencina de la Concepción (Sevilla): investigación y tutela en el 150 aniversario del descubrimiento de La Pastora: 113-130. Valencina de la Concepción-Sevilla (2010), Sevilla, Universidad de Sevilla.

Pajuelo, A. y López Aldana, P. (2013): "Estudio arqueozoológico de estructuras significativas de c/Mariana de Pineda s/n (Valencina de la Concepción, Sevilla)", en L. García Sanjuán, J.M. Vargas, V. Hurtado, T. Ruiz Moreno y R. Cruz-Auñón (eds.), El asentamiento prehistórico de Valencina de la Concepción (Sevilla): investigación y tutela en el 150 aniversario del descubrimiento de La Pastora: $445-$ 458. Valencina de la Concepción-Sevilla (2010), Sevilla, Universidad de Sevilla.

Pellicer, M.; Escacena, J.L. y Bendala, M. (1983): El Cerro Macareno. Excavaciones Arqueológicas en España 124. Madrid, Ministerio de Cultura.

Ruiz Mata, D. (1975a): “Cerámicas del bronce del poblado de Valencina de la Concepción". Madrider Mitteilungen 16: 80-110.

Ruiz Mata, D. (1975b): “Cerámicas del bronce del poblado de Valencina de la Concepción (Sevilla): los platos". Cuadernos de Prehistoria y Arqueología de la Universidad Autónoma de Madrid 2: 123-149.

Ruiz Mata, D. (1983): "El yacimiento de la Edad del Bronce de Valencina de la Concepción (Sevilla) en el marco cultural del Bajo Guadalquivir". I Congreso de Historia de Andalucía I: 183-208. Córdoba (1979), Córdoba, Caja de Ahorros de Córdoba.

Ruiz Moreno, M‥T. (1999): "Excavación arqueológica de urgencia en la urbanización de 'El Mirador de Itálica. Valencina de la Concepción, Sevilla”.
Anuario Arqueológico de Andalucía 1999. III. Actividades de Urgencia: 511-516. Sevilla, Consejería de Cultura de la Junta de Andalucía.

Ruiz Moreno, Ma .T. (2013): "La Pastora (Valencina de la Concepción, Sevilla): una historia desconocida", en L. García Sanjuán, J.M. Vargas, V. Hurtado, T. Ruiz Moreno y R. Cruz-Auñón (eds.), El asentamiento prehistórico de Valencina de la Concepción (Sevilla): investigación y tutela en el 150 aniversario del descubrimiento de La Pastora: 201-217. Valencina de la Concepción-Sevilla (2010), Sevilla, Universidad de Sevilla.

Sardá Piñero, D. (2013): "Estructuras negativas multifuncionales en Avenida de Andalucía no 9, Valencina de la Concepción (Sevilla)", en L. García Sanjuán, J.M. Vargas, V. Hurtado, T. Ruiz Moreno y R. Cruz-Auñón (eds.), El asentamiento prehistórico de Valencina de la Concepción (Sevilla): investigación y tutela en el 150 aniversario del descubrimiento de La Pastora: 151-156. Valencina de la ConcepciónSevilla (2010), Sevilla, Universidad de Sevilla.

Schuhmacher, T.; Falkenstein, F.; Link, Th.; Mederos, A. y Vargas, J.M. (e.p.): "Archäologische und geophysikalische Prospektionen im Nordbereich der chalkolithischen Siedlung von Valencina de la Concepción bei Sevilla (Andalusien) im Jahr 2014". Madrider Mitteilungen 56 (2015): 1-39.

Tavares da Silva, C. y Soares, J. (1985): "Monte da Tumba (Torrão). Eine befestigte Siedlung der Kupferzeit im Alentejo (Portugal)". Madrider Mitteilungen 26: 1-21.

Vargas Jiménez, J.M. (2003): "Elementos para la definición territorial del yacimiento prehistórico de Valencina de la Concepción (Sevilla)". Spal 12: 125 144. doi.org/10.12795/spal.2003.112.06

Vargas Jiménez, J.M. (2004): Carta Arqueológica Municipal de Valencina de la Concepción. Sevilla, Junta de Andalucía.

Vargas Jiménez, J.M. (2013a): "Indicadores arqueológicos para la planificación y gestión del yacimiento de Valencina de la Concepción (Sevilla)", en L. García Sanjuán, J.M. Vargas, V. Hurtado, T. Ruiz Moreno y R. Cruz-Auñón (eds.), El asentamiento prehistórico de Valencina de la Concepción (Sevilla): investigación y tutela en el 150 aniversario del descubrimiento de La Pastora: 535-557. Valencina de la Concepción-Sevilla (2010), Sevilla, Universidad de Sevilla.

Vargas Jiménez, J.M. (2013b): Memoria arqueológica de los hallazgos en el Camino de Valdegrillo. Valencina de la Concepción. Informe inédito. Delegación 
Territorial de Cultura y Turismo. Junta de Andalucía. Sevilla.

Vargas Jiménez, J.M.; Meyer, C. y Ortega Gordillo, M. (2012): "El tholos de La Pastora y su entorno: el sector oriental del yacimiento de Valencina a través de la geofísica". Menga. Revista de Prehistoria de Andalucía 3: 121-138.
Wheatley, D.; Strutt, K; García Sanjuán, L.; Mora Molina, C. y Peinado Cucarella, J. (2012): "New evidence on the spatial organisation of the Valencina de la Concepción Coper age settlement: geophysical survey between La Pastora and Montelirio". Trabajos de Prehistoria 69 (1): 65-79. doi.org/10.3989/ tp.2012.12080. 